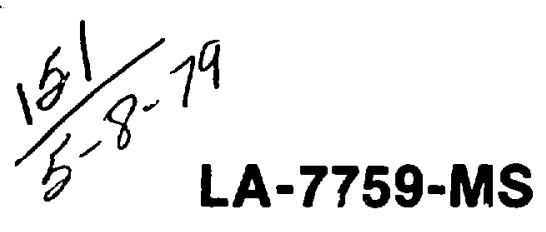

\title{
DR. 2554
}

Informal Report

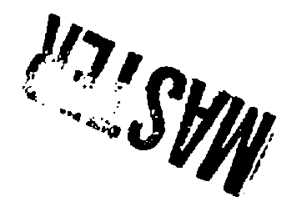

\section{Tests of Vacuum Interrupters for the Tokamak Fusion Test Reactor}

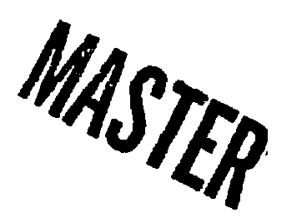

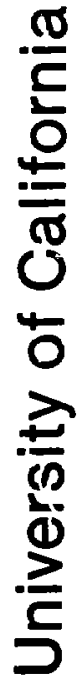




\title{
Tests of Vacuum Interrupters for the Tokamak Fusion Test Reactor
}

\author{
R. Warren* \\ M. Parsons \\ E. Honig \\ J. Lindsay
}

*Industrial Staff Member. Westinghouse Research Laboratory, 1310 Beulah Road, Pittsburgh, PA 15235.

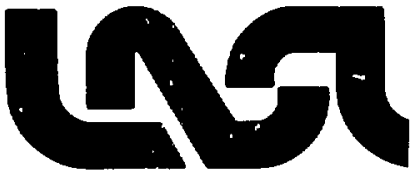


TESTS OF VACUUM INTERRUPTERS FOR THE TOKAMAK FUSION TEST REACTOR

bv

R. Warren, M. Parsons, E. Honig, and J. Lindsay

\section{ABSTRACT}

The Tokamak Fusion Test Reactor (TFTR) project at Princeton University requires the insertion of a resistor in an excited ohmlcheating coil circuit to produce a plasma initiation pulse (PIP). It is expected that the maximum duty for the switching system will be an interruption of $24 \mathrm{kA}$ with an assoclated recovery voltage of $25 \mathrm{kV}$. Vacuum int rerupters were selected as the most economical means to satist'y these requirements. However, it was felt that some testing of available systems should be performed to determine their reliability under these conditions.

Two interrupter systems were tested for over 1000 interruptions each at $24 \mathrm{kA}$ and $25 \mathrm{kV}$. One system emploved special Westinghouse type WL-33552 interrupters in a circuit designed by LASL. This circuit used a commercially avaliable actuator and a minimum size counterpulse bank and saturable reactor. The other used Toshiba type VGB2-D20 interrupters actuated by a Toshiba mechanism in a Toshiba circuit using a larger counieroulse baak and saturable reactor.

Both of these systems successfuliy completed 1000 interruptions without failure and indicated a very low contact erosion rate. Both appear to satisfy the needs of TFTR with respect to reliability and to have such low erosion rates that this feature is not expected to be a imitation on lifetime. 
PART I - WESTINGHOUSE INTERRUPTERS

\section{INTRODUCTION}

This report covers the first part of a series of tests performed by the Los Alamos Sctentific Laboratory (LASL) for Ebasco/Grumman (E/G). In these tests the performance of type WL-33552 vacuum interrupters was investigated in circuits like those to be used in the ohmic-heating subsystem of the Tokamak Fusion Test Reactor (TFTR). The circuit used is simflar to one proposed by Westinghouse for TFTR. The interrupter features spectal electrodes designed to have a long life and the use of an axial magnetic field to provide long life and high rellability. The axial field is supplied by a coll external to the interrupter. Two interrupters are used in series to enhance their individual relfabilities. The circuit features a very small capacitor to supply the counterpulse current and a special way of using the capacitor. It is $70 \mu f$ instead of a more normal 400 to $500 \mu \mathrm{f}$. It is charged to a fixed voltage which is determined by the maximum current to be interrupted. This voltage can then be used to interrupt any current up to the maximum. This mode has been demonstrated in earlier experimental work. It is a change from the normal mode in which the capacitor voltage is varied with the current to be interrupted.

The purpose of the tests reported here is to determine the actual reliability and lifetimes of the interrupter's circuit under the conditions anticipated for T.FTR. These include a maximum current of $24 \mathrm{kA}$, a current-carrying interval of about $100 \mathrm{~ms}$ that develops a $\int \mathrm{I}^{2} \mathrm{dt}$ value in the switch of $6 \times 10^{7}$ amp $^{2} \mathrm{~s}$, and a maximum recovery voltage of $25 \mathrm{kV}$ sustained for 15 ms. These conditions could all be met with simple modifications to our normal test circuit except for the large $\int \mathrm{I}^{2} \mathrm{dt}$ requirement. To meet it, extensive modiflcations were made that allowed a homopolar generator to be connected momentari1y to the interrupters under test. The homopolar heats them to simulate the extended current-carryting time of TFTR.

Because the use of vacuum inte:rupters in TFTR-1ike circuits is fairly unusual, the tests performed included experimentation and unilateral decistons by LASL about some of the circuit features, for example, the size of certain components and the timing of certain events. They also included extensive diagnosic provisions to detect malfunctions or fallures of the various components. At times failures were purposely caused to gain experience in their detection and interpretation. Because of these features of the tests, some of the results reported below were taken with component values or timings which were not optimum and did not give highly reliable interruption. In addition there was not sufficient time to explore the full range of variables, thus better operating condictons might exist outside of the range explored. Immediately below are preseited the circuit and component values used in the majority of the tests, a description of measurements routinely taken, a listing of the tests actually performed, and the results with interpretations of them. 
II. CIRCUIT AND COMPONENTS USED

The standard LASL circuit used to test single interrupters is shown in Fig. 1. It generates voltage and current waveforms in the interrupter which are shown in Fig. 2. The details of this circuit and its operation are described elsewhire. 1 These waveforms are unacceptable for E/G's purposes for several reasons: 1) the interrupter's conduction time, from $S 1$ to $S 3$ of Fig. 2, $1 \mathrm{~s}$ only $5 \mathrm{~ms}$ or so, much less than the $100 \mathrm{~ms}$ of interest, 2) the recovery voltage, $\mathrm{VC} 2$, is imposed on the interrupter for less than $1 \mathrm{~ms}$, not the $15 \mathrm{~ms}$ of interest, 3) the magnitude of $\mathrm{dV} / \mathrm{dt}$ is considerably less than that anticipated for the TFTR circuit, and 4) the interrupter recovery viltage, VC2, has a short interval of reversed polarjty, near $S 3$, which must somehow be avolded in TFTR. To correct these performance deficiencies, LASL has made extensive changes in its circuit. The resulting circuit, used in most of the tests with two interrupters in series, is shown in Fig. 3 and the values of 1 ts components are given ir. Table $I$. The features of the circuit are explained below.

TABLF, I

VALUES OF CRITICAL COMPONENTS

CI

$\mathrm{C} 2$

c3

CD

R1

R3

$\mathrm{RD}$

RL

LSR

LSR

L.

LAF1 and LAF2
$1440 \mu \mathrm{f}$

$71 \mu \mathrm{f}$

$1.9 \mu \mathrm{f}$

$250 \mu \mu \mathrm{f}$

$1000 \Omega$

$100 \Omega$

$1 M \Omega$

$1.5 \Omega$

10 gapless tape-wound ccres total flux $=0.08 \mathrm{~Wb}$

30 small gap tape-wound cores total flux $=0.12 \mathrm{~Wb}$

$140 \mathrm{HH}$ a1r-core Inductor

8 turns of 4-0 cable connected in two parallel sets of 4 turns each. Field at center is $210 \mathrm{~m} \mathbf{I}$ at $24 \mathrm{kA}$. 


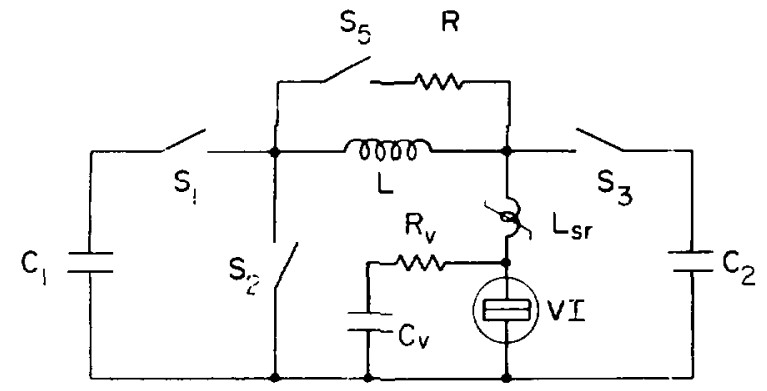

Fig. 1. Conventional LASL test circuit.

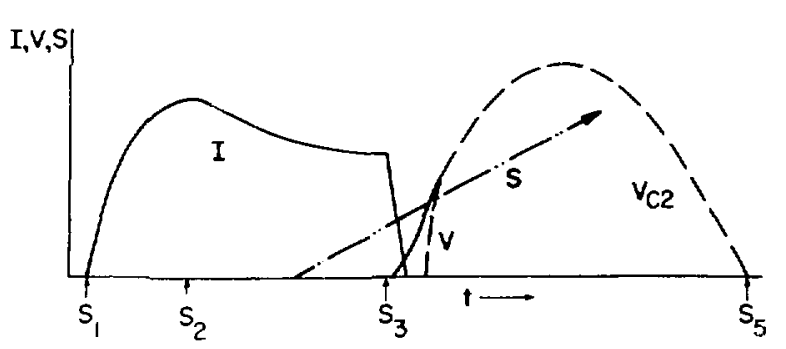

Fig. 2. Typical traces of voltage, current, and electrode motion.

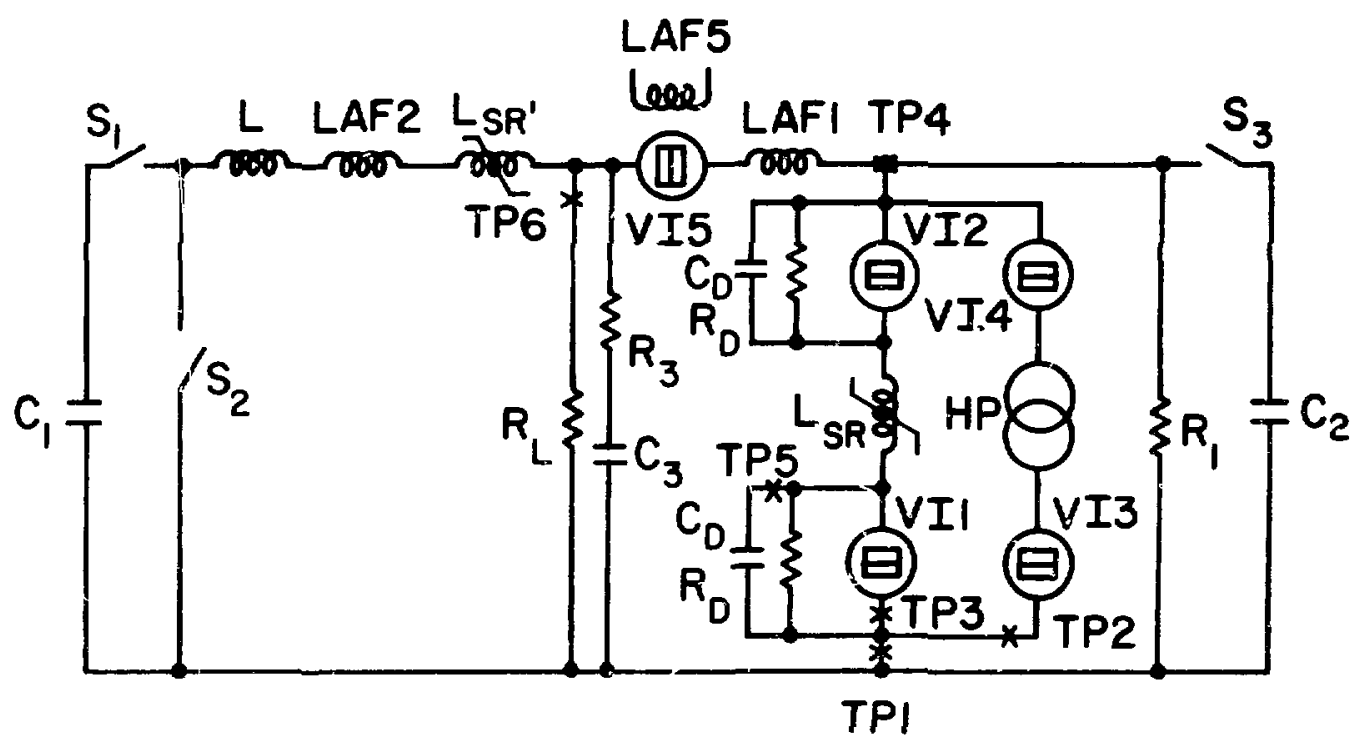

Fig. 3. LASL test circuit as modified for $E / G$ rests. 
A. Components VI 3, VI4, and HP

The homopolar generator, HP, is capable of generating $10 \mathrm{kA}$ at $7 \mathrm{~V}$ or $20 \mathrm{kA}$ at about $4 \mathrm{~V}$. It is connected to the interrupters being tested, VII and VI2, by two auxiliary interrupters, VI3 and VI4. Largely because of the resistance of the four series-connected interrupters, only $10 \mathrm{kA}$ can be generated in this circuit by HP. Interrupters VI3 and VI4 can be closed and opened quilckly upon command. Thus they can be used w1th HP to heat VI1 and VI2 to any degree desired and can then be opened just before the normal test sequence is initiated to disconnect HP completely from the normal test circuit.

This use of VI3 and VI4 and HP is not in all respects a perfect simulation of the conditions expected in TFTR. In particular, the heating current is not the full $24 \mathrm{kA}$ of TFTR, and, in addition, there is a short ( 4-ms) period fust before interruption during which the interrupter current falls to zero. Previous experiments 1 have shown that the 4-ms zero current period has no serious consequences. The effect of the mismatch of current levels is unknown.

B. Components VI5, LSR', R3, C3, and LAF5

Originally the recovery voltage was intended to be maintained at: $25 \mathrm{kV}$ on the test int orrupters by connecting a solid state diode (provided by E/G) In series with L of Fig. 1. The duty on this diode is severe because the voltage rises across it very rapidly when it ceases to conduct. The diode was Inadvertantly damaged thus another auxillary interrapter, VI5, was used in Its place. Because of the severe duty, this interrupter was assisted in every way concelvable, i.e., with an externally powered axial field coll, LAF5; with a

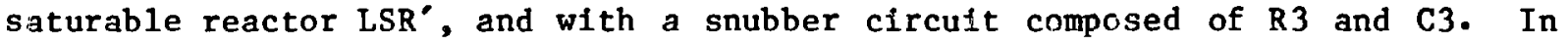
spite of these auxiliarles, VI5 was still found to restrike with a 5 to $10 \%$ probability.

\section{Component R1}

Ignitron $S 3$ presents a new problem in the modiflad clrcuit. Normally, 1t ceases conduction shortly $(\sim 1 \mathrm{~ms})$ after its current has dropped close to zero. In the new circuit, however, the ignitron must conduct during the whole $15 \mathrm{~ms}$ of maintained voltage on the test interrupters. The insertion of $R 1$ provides a "keep-alive" current of $25 \mathrm{~A}$.

\section{Components RL and $\mathrm{C2}$}

To simulate the TFTR circuit better, C2 was reduced from $180 \mu \mathrm{F}$ to $70 \mu \mathrm{F}$ and RL $(1.5 \Omega)$ was inserted. In TFTR RL $=1.0 \Omega$, but because $L$ of our test circuit is much swaller than the inductance of the ohmic-heating coil of TFTR, RL had to be increased to $1.5 \Omega$ to provide the desired recovery voltage. This causes $\mathrm{dV} / \mathrm{dt}$ to be somewhat too high.

\section{E. Special Diode}

TFTR will use a combination of series inductance and a diode to remove the reverse-voltage sp::ke mentioned above. In our circuit the inductor, $L$, and ignitzon, S2, perform this function. To guide $\mathrm{E} / \mathrm{C}$ in the design of their circuit, a special inductance-diode combination has been tested to determine the circuit parameters required to satisfy TFTR's reeds. These measurements and the parameters determined are discussed furcher below. 


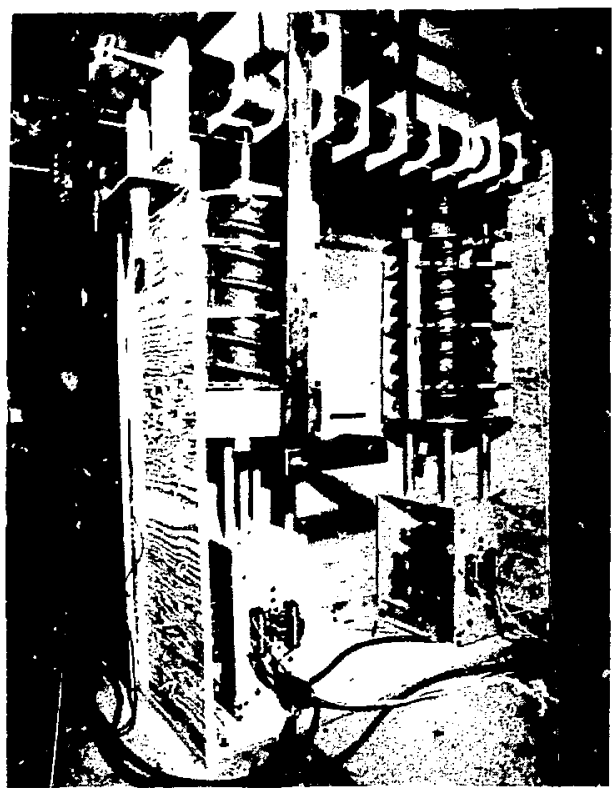

Fig. 4. Axial field coils mounted on vacuum interrupters.

F. Components $\mathrm{AAF1}, \mathrm{LAF} 2, \mathrm{CD} 1, \mathrm{CD} 2, \mathrm{RD} 1$, and RD2

Axial field coils LAF1 and LAF2 are used with the Westinghouse interrupters WL-33552 under test. Figure 4 shows these 8-turn coils surrounding tneir respective interrupters. Also shown are the actuators and saturable reactors arranged as they were used in these tests.

$\mathrm{CD}$ and $\mathrm{RD}$ are used to divide the recovery voltage equally across VIl and VI2, to provide a tast point (TP5) to signal the failure of a single interrupter, and to identify the faulty one.

\section{MEASUREMENTS ROUTINELY PERFORMED}

\section{A. Electrical}

Oscilloscopes were used to measure the voltage or current found at test points TP1 through TP6. Test points 1 and 2 are low resistance current monitors; TP3 is a Rogowski col1 current monitor; the rest are high voltage probes. TP5, TP4, and TP6 could be used respectively to measure the arc voltage across VI1, VI1 and VI2 together, and VI1, VI2, and VI5 together. More important, the timing of their contact partings could be identified and measured by using these three test points. Figure 5 showing three closely-spaced voltage jumps (labelled 1, 2, and 3) as each fnterrupter opens, is an example of the voltage at TP6. TP4 was also used to determine the overall success of an attemp sed interruption. Figure 6 shows the voltage at TP4 after a successful interruption. TP5, in contrast, gave information about the success of each of the separate series interrupiers. Ficure 7 shows the voltage at TP5 when the upper interrupter has falled (labelled F). TP1, TP2, and TP3 could be used to verify a failure and to distinguish between a failure of VI1 and VI2, VI3 and VI4, or VI5. Figure 8 shows the output of TP3 for a successful incerruption. Shown are the end of the HF current, the 4-ms current 


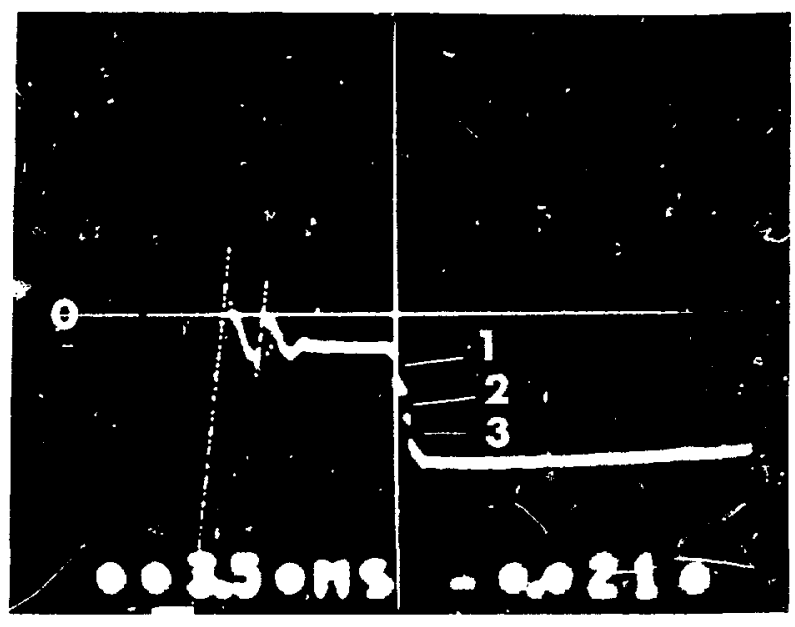

Fig. 5. Arc voltage showing closely spaced openings of VII, VI2, and VI5. The trace covers $8 \mathrm{~ms}$.

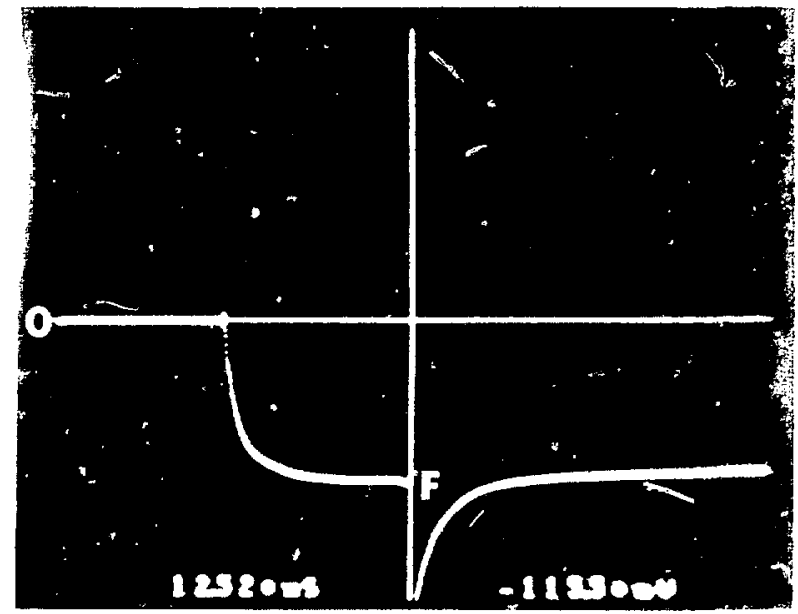

Fig. 7. Recovery voltage at the midpoint of VI1 and VI2 when VI2 has failed. The trace covers 20 ms.

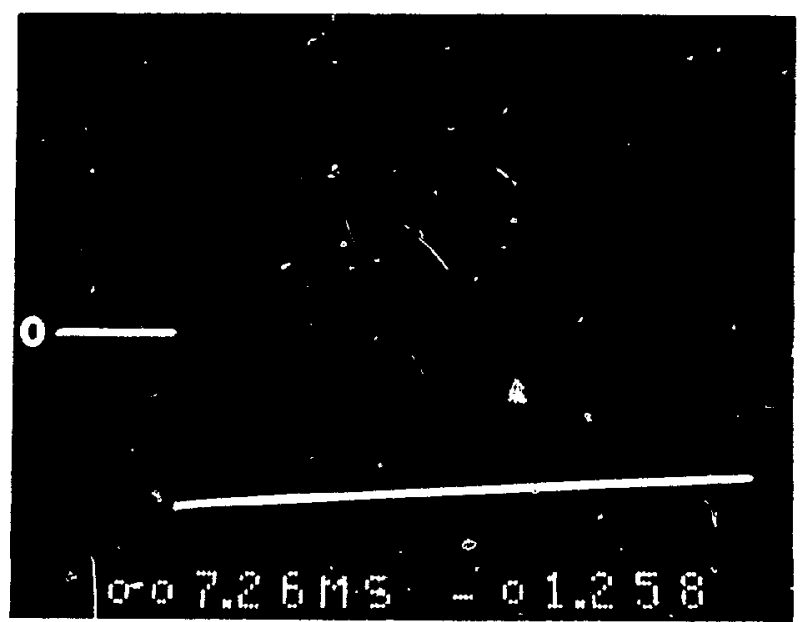

Fig. 6. Recovery voltage across VIl and VI2. The trace covers $40 \mathrm{~ms}$. The peak recovery voltage is $26 \mathrm{kV}$.

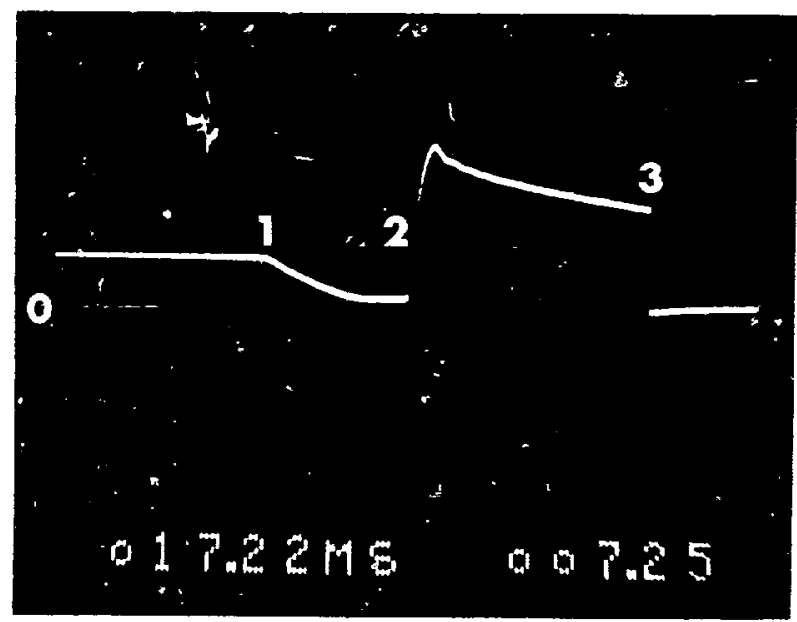

Fig. 8. HP and ncrmal test currents through VII and VI2. The trace covers $20 \mathrm{~ms}$. The test current is $25 \mathrm{kA}$. 


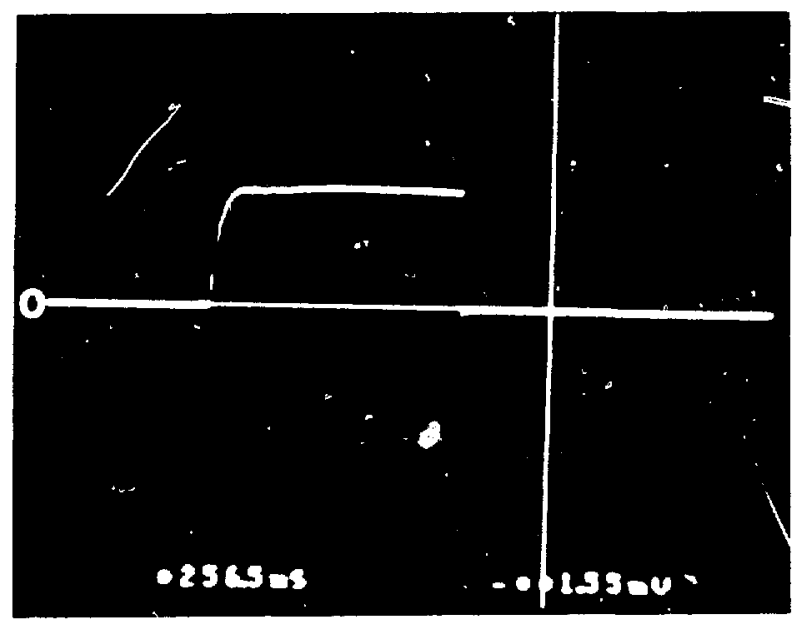

Fig. 9. Slow scan of HP current. The trace covers $2 \mathrm{~s}$. The peak current is $10 \mathrm{kA}$.

delay from 1 to 2 as VI3 and VI4 open, and then the norma1-test-sequence current waveform concluding in a successful interruption at 3 . Figure 9, showing the complete HP current waveform, gives the output of TP2 on a slow scan.

A. large number of system fallures were observed during the tests and only a much smaller number of interrupter failures. These system failures are discussed later; but at this point, the importance, during the tests, of correctly identifying the source of a failure should be emphasized. In most cases, this determination was made unequivocally. This was possible because of the excellent instrumentation, a good understanding of the circuit, and experience gained in preliminary experimentation.

\section{B. Other Measurements}

The cscilloscope traces described above provided values for currents, voltages, and the times at which various events occurred. Also, routinely measured were the spacing of the electrodes of VI1 and VI2, from which erosion data could be obtained, and the temperature of the stems of VIl and VI3. The opening speeds of VI1 and VI2 wer? measured twice during the tests.

\section{TESTS PERFORMED}

The test circuit and component values are shown in Fig. 3 and Table I. Where possible they duplicate the values specified by Westinghouse in its prcposal to $\mathrm{E} / \mathrm{G}$. To the extent possible, the tests were performed following E/G specification PPPL-i 108 as revised on March 1, 1978 and further modiffed in ongoing discussions. In particular, the conditions of Table II were met in most of the rests. 
TABLE II

EBASCO SPECIFICATIONS

Commutation time, $\leq 500$ us

Recovery voltage peak, 25 to $27 \mathrm{kV}$

Recovery voltage rise time, $\leq 500 \mu \mathrm{s}$

Recovery voltage period, $15 \mathrm{~ms}$

Dwell time, $\geq 50 \mu \mathrm{s}$, and as short as possible

Arcing gap, $\simeq 7 \mathrm{~mm}$
TEST

CONDITIONS

50 us

25 to $26 \mathrm{kV}$

$80 \mu \mathrm{s}$

40 to $400 \mathrm{~ms}$

30 Hs

$\sim 7 \mathrm{~mm} \cdot$

The other important parameters 1isted in paragraph 11.1 .5 of PPPL-1108 were rcutinely recorded or are calcuable from recorded data.

The tests were conducted in 13 sets, where enough tests were performed in each set to provide data of some statistical value, and, where, usually, only one significant parameter was changed between sets. A total number of tests in excess of 1000 were performed at full current and with $I^{2} t$ heating to provide the crucial data on reliability and erosion. Table III lists the different sets and the pertinent information for each. In the table, $\Delta t$ is the interval between shots, $t_{\text {arc }}$ the arcing time, $B_{a x}$ the axial field, $v_{s}$ a sustained recovery voltage, $I^{2} t$ the integrated value of the square of the heating current, and "failures" lists the number of double and single interrupter failures observed. The results of the tests will be discussed in the order shown in the Table.

TABLE III

TESTS PERFORMED

Test

เiL. $-33552 \mathrm{~A}$

biL-33552B

$A \& 5$ in Series

A \& B in Series

$A$ \& B In Series

A \& B in Serieg

A \& B in Serles

$A$ \& $B$ in Series

$A$ \& in Series

$A$ o $b$ in Serles

$A$ \& B in Serles

A \& is in Series

WI. $-33552 \mathrm{~B}$

Lt
(M1
2
2
2
2
2
2
2
2
2
2
2
3
2
-

$$
\underset{\text { (ms) }}{\text { tarc }}
$$$$
\left(\times 10^{7} A^{2} \mathrm{~s} s\right)
$$

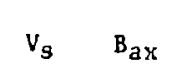

$\underset{(\mu \mathrm{f})}{\mathrm{C}_{2}}$

6.0

6.0

5.0

5.0

5.0

7.0

7.0

7.0

7.0

7.5

7.5

4. 8

$-$

$C_{2}$
$(\mu \mathrm{f})$

187
150
150
71
71
71
71
71
71
71
71
71
71

RL

Failures

(I) (Double/Single)

Tests at $24 \mathrm{kA}$

$\infty$

$\infty$

1.5

1.5

1.5

1.5

1.5

1. 5

1.5

1.5

1.5

1.5

$0 / 0-1$
$0 / 0$
$0 / 0$
$2 / 3$
$0 / 1$
$0 / 0$
$0 / 1$
$0 / 0$
$0 / 0$
$0 / 1$
$0 / 0$
$0 / 0$
-

B7

176

315

26

38

20

15

192

315

105

2 


\section{A. Single WL-\$352A}

Currents were Increased in 5-kA steps from 5 to $30 \mathrm{kA}$. At each level a variety of counterpulse voltages were used. No failures were seen. Finally 87 tests were performed at $24 \mathrm{kA}$. One fallure was observed among these 87 . The jitter In cortact opening time was $\pm 0.3 \mathrm{~ms}$. No contact erosion was seen, Instead a gradual growth, due probably to contact roughening, was noted.

B. Other Single wL-33552B

Currents were increased from 5 to $30 \mathrm{kA}$ in 5-kA steps. Finally 176 shcts were fired at $24 \mathrm{kA}$. No failures were observed. Jitter and erosion comparable to $A$ above were seen.

C. Two WL-33552 in Series

Recovery voltage was sustained for $15 \mathrm{~ms}$ or more for the first time by use of VI5. Current was increased from 5 to $25 \mathrm{kA}$ in 5-kA steps. A current of $30 \mathrm{kA}$ could not be reached due to equipment limitations. Finally, 315 tests were fired at $24 \mathrm{kA}$. No fallures of any kind were observed, but for 200 of these tests some of the instrumentation was disconnected so that a single interrupter fallure would not have been observed. Some second zero interruptions were seen, indicating that the interrupters were operating fairly close to their 1imit. Little erosion was noted; in fact, an apparent $\varepsilon$ rowth of the electodes was measured due, presumably, to surface roughening.

\section{Two in Series, HP on, and C2 Reduced to $70 \mu \mathrm{F}$}

Twenty-six tests were fired at $24 \mathrm{kA}$. Many restrikes were observed. Two were simultaneous restrikes of both interrupters; three were restrikes of single interrupters. Earlier experience and subsequent findings indicate that these restrikes were caused by a combination of events including an arcing time which was too short, the deleterious effects of the extra $\mathrm{I}^{2} \mathrm{t}$ contact heating, and extra-large fitter in opening time caused by a broken anchor in the actuator, discovered about 100 tests later. See I below.

E. Repeat of D With HP Off

One single interrupter restrike was observed out of 38 tests at $24 \mathrm{kA}$. This indicates that $\mathrm{I}^{2} \mathrm{t}$ heating was not the only cause of trouble in $\mathrm{D}$.

F. Repeat of E With 7-ms Arcing Time

No restrikes of any kind were observed in 20 tests at $24 \mathrm{kA}$. This Indicates that a short arcing time was part of the trouble in $D$.

G. Repeat of F With HP on at $I^{2} t=6 \times 10^{7}$

One single interrupter restrike was observed out of 90 tests at $24 \mathrm{kA}$. The broken mechanical link was then found and repaired. This indicates that $I^{2} t$ heating doesn't cause trouble. 
H. Repeat of F With HP Off

No restrikes of any kind were observed in 15 tests at $24 \mathrm{kA}$.

I. Repeat of H With HP On

No restrikes of any kind were observed in 192 tests at $24 \mathrm{kA}$. Thus the many restrikes observed in $D$ were eliminated by lengthening the arcing $t$ ime and fixing the broken link.

J. Repeat of I With Arcing Titne of $7.5 \mathrm{~ms}$

One single interrupter restrike was observed in 315 tests at $25 \mathrm{kA}$.

K. Repeat of $\mathrm{J}$ but $\mathrm{I}^{2} \mathrm{t}=10 \times 10^{7}$

No restrikes of any kind were observed in 105 tests.

L. Repeat of J With Arcing Time Reduced to $4.8 \mathrm{~ms}$

No restrikes of any kind were observed in 54 tests.

M. Fault Test

A fault test was performed at the maximum current of our system. The maximum current was achleved by connecting a second bank of capacitors, $\mathrm{Cl}$, in parallel with the first and discharging them both simultaneously from their maximum voltage through VI2. VI1, VI3, VI4, and VI5, as well as LS1 and LAF1 were removed from the circuit interrupter. VI2 was not purposely opened during this test but did so spontaneously because of magnetic popping forces. The Interrupter's voltage vaveform, shown in Fig. 10, reveals this popping by the periodic addition of the arc voltage to the normal resistive part of the total voltage drop. The peak current reached during two fault tests of this type was $86 \mathrm{kA}$, and the duration was absut $50 \mathrm{~ms}$. Figure 11 shows a representative current waveform.

The fault test was relatively uneventful. The interrupter was lightly welded shut after both of these tests. It could be broken loose with a moderate manual pull. High potential tests showed that the vacuum integrity was uneffected by the fault test. The stationary stem was badly bent due to mechanical forces exerted on $1 t$ by the leads to the interrupter. These had not been designed to resist the magnetic forces developed during the fault test. Figure 12 shows the bent stem after the interrupter's envelope was removed.

\section{SPECIAL DIODE TESTS}

The test clrcult of Fig. 1 was modified for these tests by dividing Inductor $L$ into two parts, $(\mathrm{Ll}=30 \mathrm{mH}, \mathrm{L} 2=110 \mathrm{mH}$ ) and connecting a diode from thisir midpoint to ground. Flgure 13 shows this part of the clrcult and various test points, TP7 through TP11, used to monitor the voltages and currents. Test point TP9 is a curreni monitor, and the otherg are voltage monttors. The diode used was manufactured by Semtech Corporation ${ }^{2}$ to meet the current, voltage, and energy dissipation speciffcations. Physically it is about $0.6 \mathrm{~m}$ long and $0.15 \mathrm{~m} \times 0.22 \mathrm{~m}$ in cross section. 


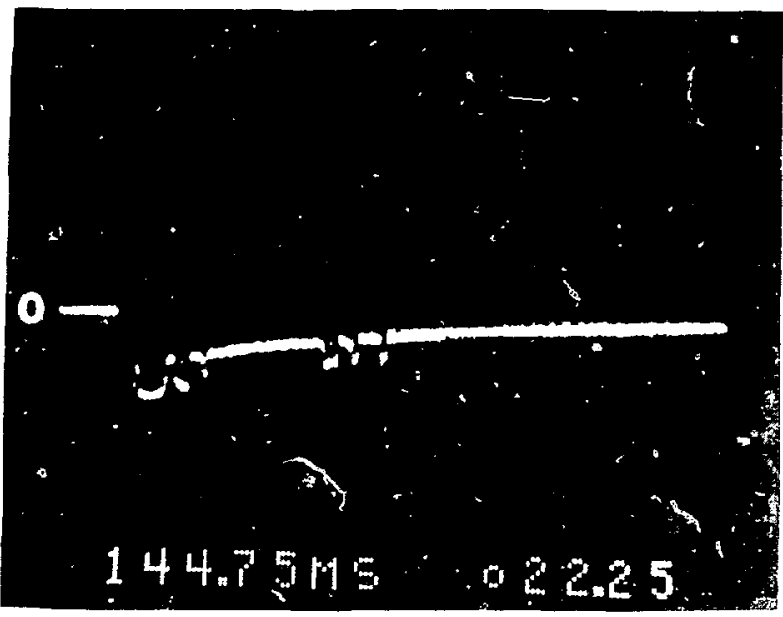

Fig. 10. Interrupter voltage during fault test. The trace covers $100 \mathrm{~ms}$. The peak voltage is $80 \mathrm{~V}$.

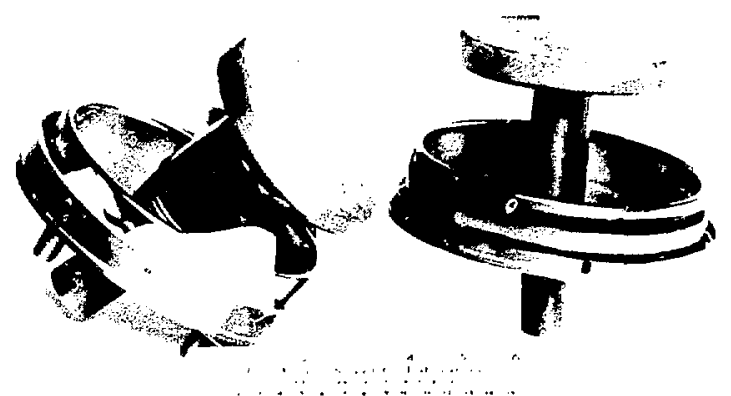

Fig. 12. Vacuum interrupter after envelope was removed.

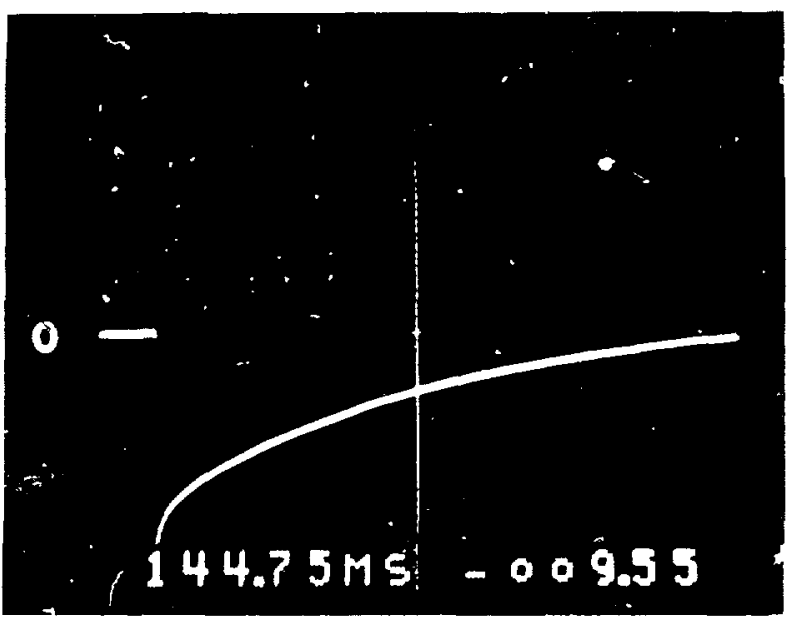

Fig. 11. Interrupter current during fault test. The trace covers $100 \mathrm{~ms}$.

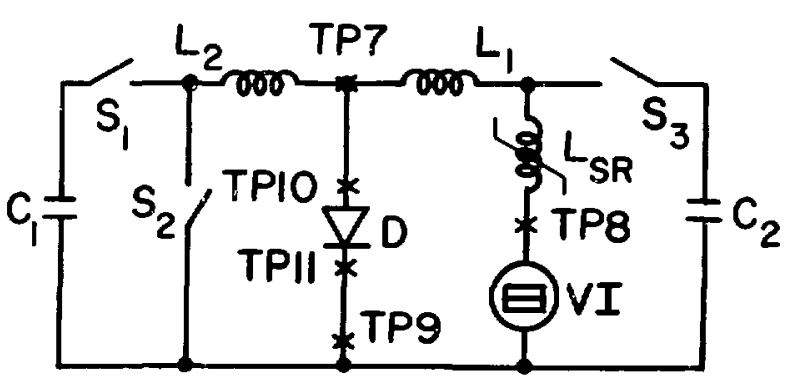

Fig, 13. Modified circuit for diode tests. 
Tests were performed with this diode in the circuit of Fig. 13 to establish those parameters of the diode which would be important to its use in the TFTR circuit. Its purpose there is to supress reversed-voltage spikes introduced by the vacuum interrupters. Since the test circuit already limits these spikes through the action of inductor $L$ and the ignitron pair S2, there was no need to use the Semtech diode as a part of the normal test circuit at the ful1 current level of $24 \mathrm{kA}$. Instead, most measurements were performed near $5 \mathrm{kA}$ but with an unusually large counterpulse voltage. This combination produces large spikes but is unlikely to overstress the diode. This cautious approach was stimulated by earlier experfence with another diode which was damaged when operated near its design limits because of a faulty circuit element.

To indicate the nature of the spike to be supressed, FIg. 14 shows a typical trace of the voltage measured at TP8. The offending spike at the beginning of the trace has two distinct parts, the first due to LdI/dt, where L is the stray inductance in the interrupter leg of the circuit (a few microhenries) and $\mathrm{dI} / \mathrm{dt}$ is the rate of change of the counterpulse current in that leg. The second part of the spike is initiated by the interruption of the current at its first zero. After interruption, the voltage at TP8 rapidly rises to the voltage on $\mathrm{C} 2$. This residual voltage is a small fraction (say $10 \%$ ) of the voltage originally present on this capacitor. In the TFTR circuit it will be approximately $1 \mathrm{kV}$, and the whole spike will last about $50 \mathrm{~ms}$.

Figure 15 shows the voltage measured at TP10. This voltage differs from that shown on Fig. 14 due to the filtering action of the combination LSR/C2 followed by that of L1/D. Measurements, not shown, confirm that LSR/C2 has little affect on the waveform other than to remove some of the sharp leading edges of the spikes. The LI/D combination is wholly responsible for the marked reduction in the area of the spikes. The desired information concerning the parameters of the diode can be extracted from the shape of traces such as these.

Figures 16-18, for example, show on expanded traces the diode current and the voltage at TP10 and TP11, 1.e., at both ends of the diode. Figure 18, the voltage at the lower end, is the voltage to be expected across a pure inductor of value $\sim 0.7 \mathrm{mH}$. This inductor is made up of an approximately $0.3-\mathrm{m}$ length of 4-0 cable connecting the diode to ground. The difference between Figs. 17 and 18 is caused by the impedance of the diode. Analysis of this difference leads to an equivalent circuit for the diode composed of a series conn stion of a perfect diode, an inductor, a resistor, and a battery. The values found for the parasitic components are $\sim 1 \mathrm{mH}, 40 \mathrm{~m} \Omega$, and $100 \mathrm{~V}$. Their combination accounts for the peak voltage of $224 \mathrm{~V}$ at $5.4 \mathrm{kA}$ shown in Fig. 17 . It would generate a peak voltage of several hundred volts if it were used in TFTR at $24 \mathrm{kA}$ with a normal counterpulse and with the filter inductor that was used in these tests.

This peak voltage could be too high for certain uses. It could be reduced efther by increasing the value of $\mathrm{L} 1$ or by reducing the parasitic components in the diode. Certainly when connecting $D$ into the TFTR circuit, care must be taken to reduce its lead inductance to well below $1 \mathrm{mH}$. 


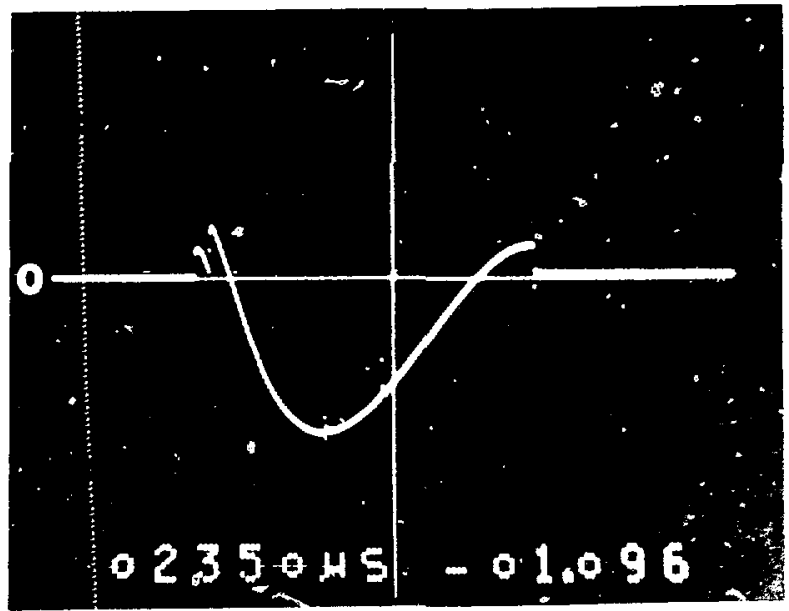

Fig. 14. Voltage across interrupter. The trace covers $1.0 \mathrm{~ms}$.

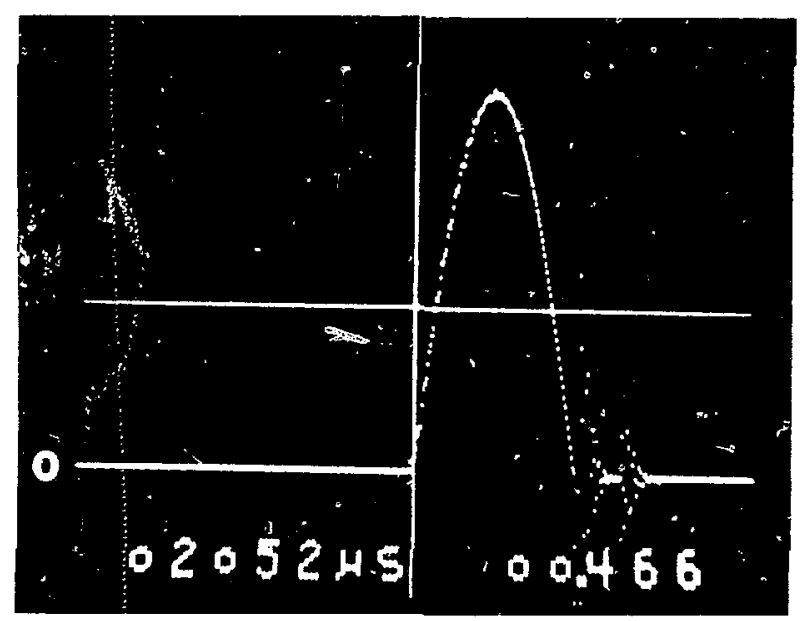

Fig. 16. Current through diode. The trace covers $0.5 \mathrm{~ms}$.

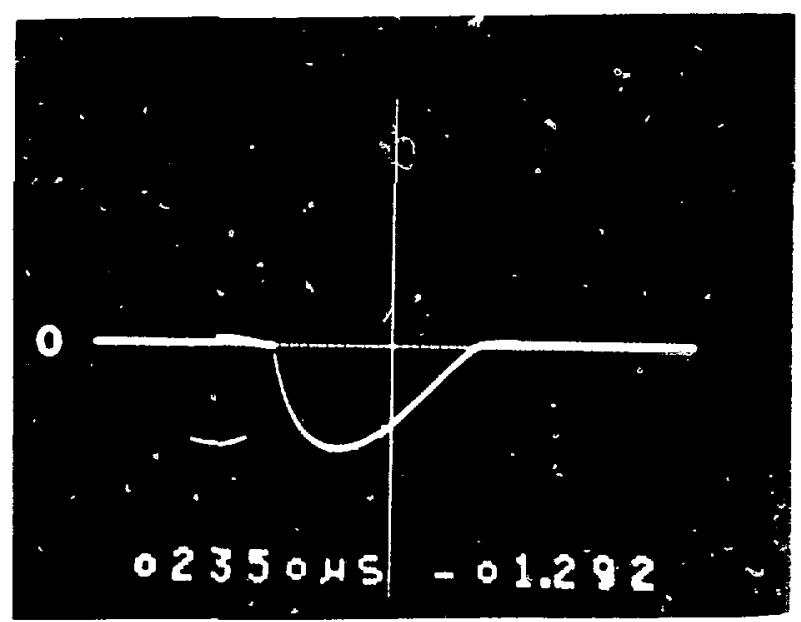

Fig. 15. Voltage across diode. The trace covers $1.0 \mathrm{~ms}$.

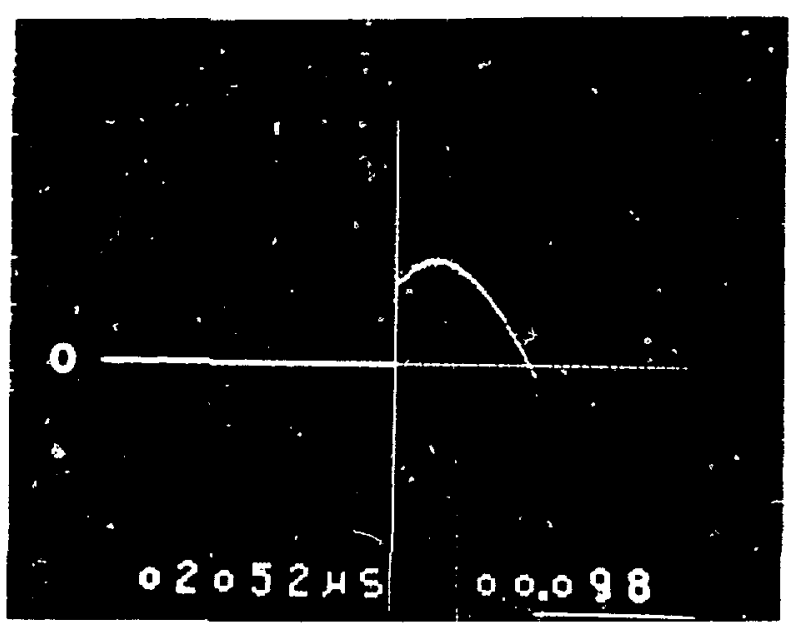

Fig. 17. Voltage across diode. The trace covers $0.5 \mathrm{~ms}$. 


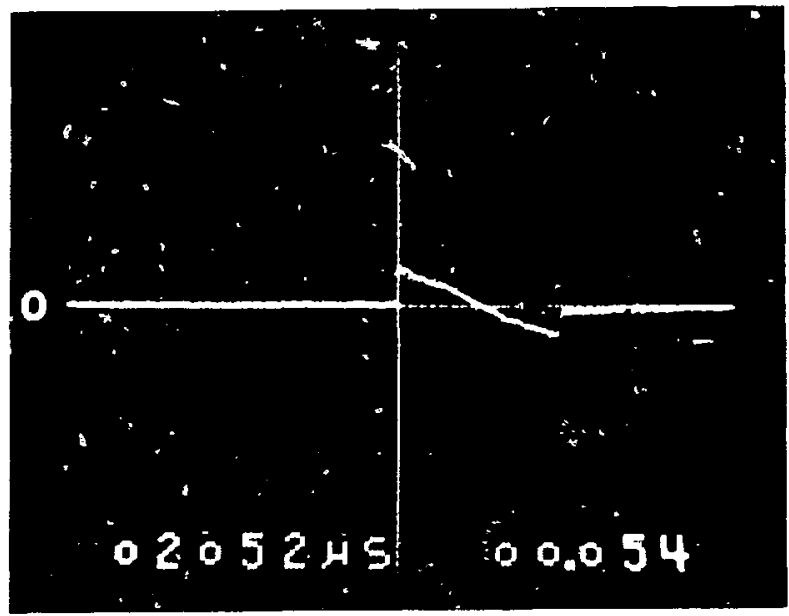

Fig. 18. Voltage across ground lead to diode. The trace covers $0.5 \mathrm{~ms}$.

VI. DISCUSSION OF RESULTS

\section{A. Reliability of Interrupters}

As mentioned in the introduction, these tests were ferformed under a variety of conditions, timings, and component values. Some conditions are favorable for reliable interruption and some are not. Two tasks are undertaken in this part of the report. These are, first, to discriminate between the favorable and unfavorable condtions and then to evaluate the rellability of interruption and the lifetime of the vacuum interrupters under the favorable conditions.

From all 1435 of the tests with the WL, -33552 vacuum interrupters listed in Table II, two restrikes were observed of the compiete interrupter, 1.e., simultaneous restrikes of both serles interrupters, and seven restrikes of single interrupters. These restrikes were not distributed randomly, however. Most of them occurred in series D which included only 26 tests. Clearly something was wrong during this series. It appears that the reliability was adversely affected by a combination of three factors - short arcing time, homopolar heating, and a broken actuator link. It this series is omitted because of unfavorable conditions and the rest of tests $A$ to $L$ retained in the data base, no complete failures were observed but a total of four single interrupter failures out of 1407 tests. On the other hand, a short arcing time appears to be the major harmful affect. If instead of omitting only run $D$, all data are discarded for arcing times of $5 \mathrm{~ms}$ or less, that is runs $C, D, E$, and $L$, then there are no complete failures, and a total of three single interrupter fallures occurred out of 1000 tests.

It must be recognized that the data presented above include two quite different subsets: series $A$ and $B$ in which a single interrupter was tested at $25 \mathrm{kV}$, and series $C$ through $L$ in which two interrupters were tested in series 
at a total voltage of $25 \mathrm{kV}$. From serles $A$ and $B$ one can derive a probability of $1 / 263$, 1.e., $0.4 \%$ that a single interrupter will fall. From the remaining serles a probability of $3 / 2288$, 1.e., $0.13 \%$, or $2 / 1474,1 . e ., 0.14 \%$ can be found for a single interrupter fallure, essentially independent of which series Is discarded for unfavorable conditions. Although the difference between $0.4 \%$ and $0.13 \%$ is large and indicates that, as expected, the fallure rate at $25 \mathrm{kV} /$ interrupter is greater than at $12.5 \mathrm{kV} /$ interrupter, the data have too much probable error to fustify this conclusion. Other information indicates that the dependence of rellability upon voltage 1s quite small. We, therefore, chose to lump all of our data together and find an average fallure rate for a single interruptar of $0.16 \%$. Now if two interrupters are connected in series, the combination will fall only if both fall. The probability of this appears at first to be the square of $0.16 \%$, $1 . e ., 2.5$ parts per million, but the conclusion is wrong and pessimistic. The reason for this involves the ability of a single interrupter in a series pair to recover rapidly its insulating properties after a fallure. This recovery occurs because of the circult configuration used. A single falled interrupter can conduct only for a limited time, $t_{o}$, before the voltage across it drops to zero and the remaining unfailed interrupter sustains all of the voltage. This time, $t_{0}$, is determined by the stze of the capacitor in parallel with each interrupter. After $t_{0}$, the

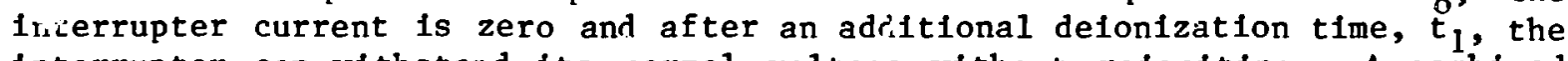
interrupter can withstand its normal voltage without reigniting. A combined failure of both interrupters w11 occur then only if the second interrupter falis within a time, $t_{0}+t_{1}$, after the first.

ne can calculate the probability of such a combined failure and compare it with the square of the probability of a single fallure to show their difference.

Let $p \equiv$ probability/sec for failure of a single interrupter

and $P l(.015) \equiv$ probability that a single interrupter fails in a $15 \mathrm{~ms}$ interva1.

Then $P l(.015)=p \times 1.5 \times 10^{-2}$.

Now $P 2(.015) \equiv$ probability of a combined fallure in $15 \mathrm{~ms}$. $\mathrm{P} 2(.015)=2 \mathrm{P} 1(.015) \mathrm{Pl}\left(\mathrm{t}_{\mathrm{o}}+\mathrm{t}_{1}\right)=2 \mathrm{p}^{2} \times 1.5 \times 10^{-2} \times\left(\mathrm{t}_{\mathrm{o}}+\mathrm{t}_{1}\right)$.

Thus $\frac{\mathrm{P} 2(.015)=}{\mathrm{P} 1(.015)^{2}} \frac{2 \mathrm{p}^{2} 1.5 \times 10^{-2}\left(\mathrm{to}_{\mathrm{o}} \mathrm{t} 1\right)}{\mathrm{p}^{2}\left(1.5 \times 10^{-2}\right)^{2}}=2 \frac{\left(\mathrm{t}_{\mathrm{o}}+\mathrm{t}_{1}\right)}{1.5 \times 10^{-2}}$.

If $\mathrm{t}_{\mathrm{o}}+\mathrm{t}_{1}=75 \mathrm{\mu s}$, which appiars to be easily achievable, $\mathrm{P} 2 / \mathrm{Pl}^{2}=0.1 \%$.

Now the selected data, which show zero combined failures in about 1000 interruptions, are not sufficient to distinguish between these two models. It appears, however, that the combined fallure rate will be less than 2.5 parts per million and far below $0.1 \%$, the fallure rate which must not be exceeded to meet the needs of TFTR. 
Most of the data was taken with $\int I^{2} \mathrm{dt}$ heating values of $6 \times 10^{7} \mathrm{~A}^{2} \mathrm{~s}$ or more. The reported fallure rate of $0.2 \%$ thus corresponds to this amount of electrode heating. The data taken without heating are insufficient to allow an Independent fallure rate determination. Other data, however, suggest that the effect of this amount of heating on the fallure rate is small.

\section{B. Erosion of Interrupter Contacts}

A plot of the erosion results is no shown because the measured erosion is very small and in most cases of negative sign, $1 . e$. , indicating growth not erosion. Instead, $x$-ray images were made of the electrodes, and finally, one interrupter was broken open to provide an unobstructed view of the electrodes. Figure 19 shows a photograph of the electrodes of this interrupter. There has clearly been pitting of both electrodes, extensive melting of their surfaces, and a net transport of a small amount of electrode material from the perimeter of the cathodes to the perimeter of the anodes. A fine metallic ridge has built up around the anodes which has, in some cases, broken loose or transferred to the cathode. The average thickness of the electrodes has not changed within $\pm 0.01 \mathrm{in.}$, the precision of the original measurement. This erosion rate is much less than that of conventional interrupters previously measured. Some very minor spattering of melted material onto the shield structure is apparent. It appears that a projected contact life of ten thousand operations is feasible before a significant change in electrode shape or build up of spattered or evaporated deposits w1ll occur. A pertodic reversal of anode-cathode roles would probably extend this life significantly.

Performing typical interruptions on a two-minute cycle caused the outer extremity of the stationary stem of VIl to reach an average temperature of $100^{\circ} \mathrm{C}$. This temperature was approached with a time constant of several hours. When the standard $I^{2} t\left(6 \times 10^{7} A^{2} s\right)$ preheating cycle was eliminated and interruption proceeded normally otherwise, the stem temperature increased only half as much. This shows that the electrode heatings during arcing and during the preheating phase were of similar magnitude. Calculations of these heat

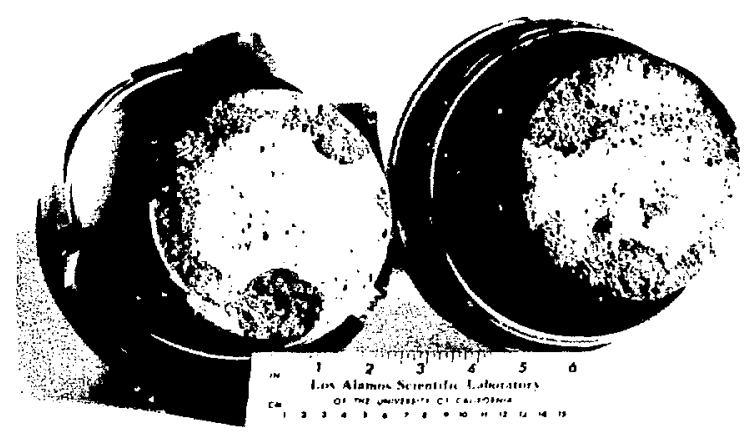

Fig. 19. Electrode surfaces of opened bottle. 
depositions with an arc voltage of $50 \mathrm{~V}$ and an electrode resistance of $100 \mathrm{~m} \Omega$ confirms this rough equality. As a consequence, an $I^{2} t$ value of $6 \times 10^{7} \mathrm{~A}^{2} \mathrm{~s}$ is expected to be critical. Below that value the $\mathrm{I}^{2}$ heating does not contribute significantly to the total heat developed in the electrodes and thus would not be expected to affect the rellability of interruption. Above that value the $I^{2} t$ heating would have a significant affect on electrode temperature and might have a significant affect on interription. 0ther measurements made at LASL, indicate that $6 \times 10^{7}$ is a low value and that much higher $I^{2} t$ values can be tolerated without significant changes in rellability. The effect on contact melting and erosion due to the $I^{2} t$ heating is unknown but may be significant.

\section{Actuator Performance}

Five Ross actuators ${ }^{3}$ were used to open and close VIl through VI5. The reliability and maintainability of these actuators were of constant concern. During the tests the following fallures were observed:

1. A microswitch and its leads failed causing unusually slow electrode separation.

2. A mechanical hinge pin became loose completely inhibiting the opening of VI2.

3. An anchor bolt broke causing a large increase in opening jitter and an unusually slow electrode separation of VIl.

4. A clamp on a stationary stem loosened increasing the heating of that electrode on VI2.

5. A mechanical connection to the moving stem loosened increasing the opening jitter of two different interrupters.

6. A microswitch adjustment shifted causing VIl to bounce closed regularly after a successful interruption.

High speed photographs were taken of the motion of the actuators for VIl and VI2. From these actuator photos, conclusions could be drawn concerning the opening speeds of the electrodes of these two interrupters. Maximum speeds of $2.6 \mathrm{~m} / \mathrm{s}$ were found for VIl and $1.6 \mathrm{~m} / \mathrm{s}$ for VI2. Corresponding electrode spacings were 0.6 and $0.4 \mathrm{~cm}$ at a $4-\mathrm{ms}$ arcing time and 1.4 and $0.9 \mathrm{~cm}$ at a $7-\mathrm{ms}$ arcing time. The large difference between these results for the two interrupters is not understood. Their actuators and drivers were checked for malfunctions and were readjusted to simflar mechanical and electrical specifications with no affect. Both actuators were quite old and have had several parts replaced due to wear. This wear and refitting somehow may have caused the large differences observed.

Previous measurements with other interrupters have shown that electrode gaps of $0.7 \mathrm{~mm}$ or more are desirable for low restrike probability. 'Thus the several fallures observed with arcing times of 4 to $5 \mathrm{~ms}$ appe - to be caused mainly by insufficient gaps. 
D. System Re11ab111ty

The overall system rellability during the tests was very poor compared to the reliability found for the interrupters. Part of this was related to components such as VIS, which sees extremely severe duty and which would rot be included in the switch used in TFTR. Other sources of fallure, however, would cause troubie in TFTR and will be mentioned here to emphasize the attention which must be pald to their design and construction to avold simllar troubles. These troubles were of three types - Ignitron prefires, electrical pickup, and mechanical shocks caused by the large magnetic forces. Ignitron prefires became progresslvely worse above $10 \mathrm{kV}$ but could be avolded or greatly reduced by cooling the cathodes and heating the anodes. Electrical pickup can be reduced by care in grounding and shielding, but this care must be exercised from the initial desig:l phase. Plckup problems were largely created by circuit changes introduced to meet the various E/G specificlations. Mechanical shock problems can be reduced by using large conductors with bolted or soldered connections liberally supported and insulated from ground.

E. Special Diode

No trouble is expected with this diode as long as (1) the inductance, L1, in sertes with it is large enough, (2) the lead inductance of the diode 1s kept sma11, and (3) the diode is protected against faults of varlous kinds in the rest of the circuit that might cause 1 ts destruction.

VII. CONCLUSIONS

When tested in its proposed circult under the proposed mode of operation, the WL-33552 interrupters behaved about as expected. When conditions were unfavorable, i.e., when the arcing gap was too short, interruption was unreliable. When operated with an adequate electrode gap (7 mm) the interrupters opened $24 \mathrm{kA}$ at $25 \mathrm{kV}$ with a fallure rate of $0.2 \%$ or so for a single interrupter. No failures were observed for two interrupters in series. The measured erosion rate was very $10 \mathrm{w}(\leq 0.1 \mathrm{~mm} / 1000$ shots) but some electrode material melted or otherwise migrated to the perimeter of the electrodes and to the anode. The rate of spattering of electrode material to the shield or Insulating structures was very low. I $I^{2}$ heating values of 6 or $10 \times 10^{7} A^{2} \mathrm{~s}$ appear to have no significant affect on reliability and probably no effect upon erosion.

The fault test was performed at $85 \mathrm{kA}$, well below the value of interest to $E / G$. Its very mild consequences, however, lend some credence to the opinion that no serious explosions will accompany a full fault. 
PART II - TOSHIBA INTERRUPTERS

I. ENTRODUCTION

The purpose of this segment of tests was to determine the reliability and erosion rate of two, series-connectel Toshiba type VGB2-D20 vacuum interrupters. As in the Westinghouse tests, the interrupter was specified to operate at $24 \mathrm{kA}$ with a recovery voltage of $25 \mathrm{kV}$. In this set of tests, however, there was to be no external $I^{2} t$ heating, so that the total heating, primarily during the arcing interval, was approximately $8 \times 10^{6} \mathrm{~A}^{2} \mathrm{~s}$. These tests also differed from those conducted on the Westinghouse interrupters in that the counterpulse bank and saturable reactor were specified by Toshiba at values considerably larger. This subjected the vacuum interrupter under test to lower values of $\mathrm{dI} / \mathrm{dt}$ and $\mathrm{dV} / \mathrm{dt}$. Both the total and midpoint voltages across the series interrupters were monitored for $30 \mathrm{~ms}$ following interruption. This allowed detection of double or single interrupter restrikes during this pertod. Erosion rates were also measured for both interrupters during all the standard tests.

In addition to the above tests, a set of extended tests on a single-interrupter Toshiba interrupter were performed to determine the upper-1imit interruption ability. Toshiba International imposed, for these tests, certain constraints on the critical parameters. The extended tests section of this report discusses these in detail.

\section{STANDARD TESTS}

Figure 20 is a schematic of the circuit used in the standard tests. It differs from the circuit used in the Westinghouse tests in that there is no homopolar generator for $I^{2} t$ heating, the counterpulse capacitor and saturable reactor are changed, and the test interrupters have internal axial-field colls. Current is initiated by discharging the $2760-\mu \mathrm{F}$ sapacitor through the $200-\mu \mathrm{H}$ inductor, the blocking circuit, the $407 / 110-\mu \mathrm{H}$ saturable reactor, and the Toshiba vacuum interrupters. The series ignitrons on the left prevent voltage reversal on the $2760-\mu \mathrm{F}$ capacitor and thereby initiate an exponential decay after current peak is reached. All three vacuum interrupters are then opened and the $4 j 0-\mu F$ counterpulse capacitor is discharged. This drives the current in the Toshiba interrupters to zero where interruption occurs. The remaining energy in the $200-\mu \mathrm{H}$ inductor then transfers to the counterpulse capacitor where it is held by the blocking circuit. The $1-k \Omega$ resistor maintains the voltage across the test Interrupters by keeping the ignitrons conducting.

The 407/110- $\mathrm{H}$ saturable reactor was iesigned to meet the specifications in Fig. 21 supplied by Toshiba.

Firing sequences were controlled with a digital delay generator through fiber-optic cables. The control cabinets and digital oscilloscopes are shown $+F 1 g \cdot 22$.

F1gure 23 is a photograph of the Toshiba interrupter installed in the facllity for tests. 


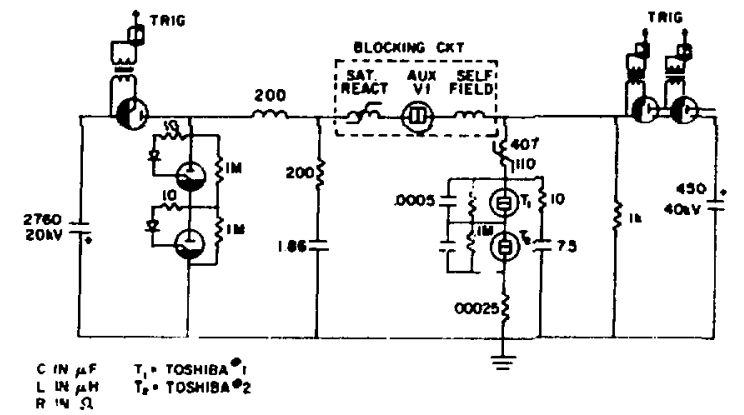

Fig. 20. Circuit for standard Toshiba tests.

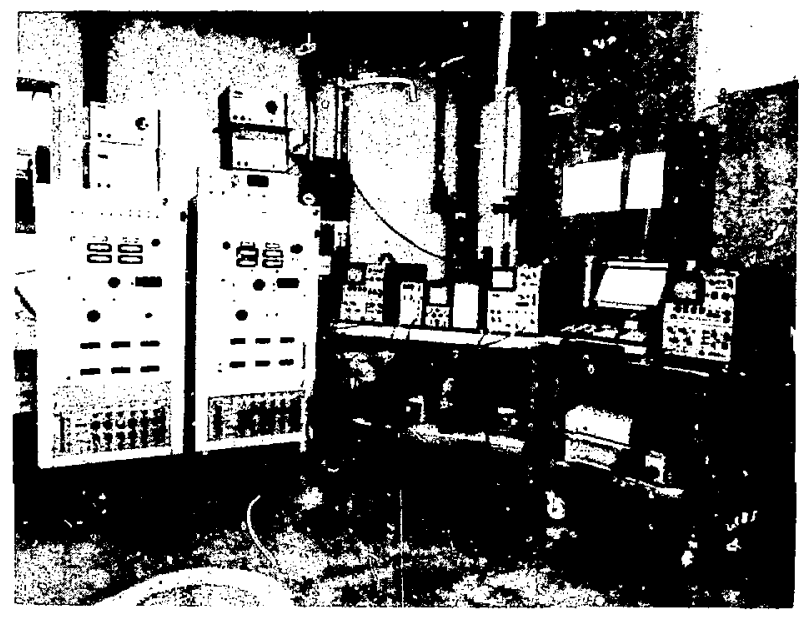

Fig. 22. Control cabinets with digital delay generators and digital oscilliscopes.

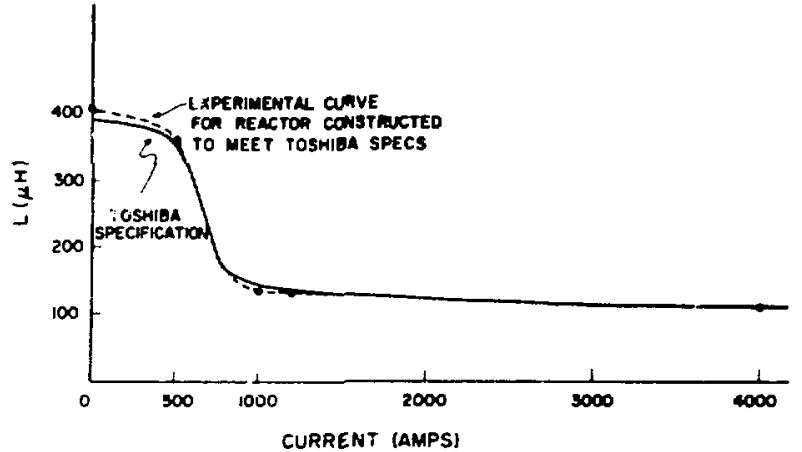

Fig. 21. L-I characteristics of saturable reactor for standard tests.

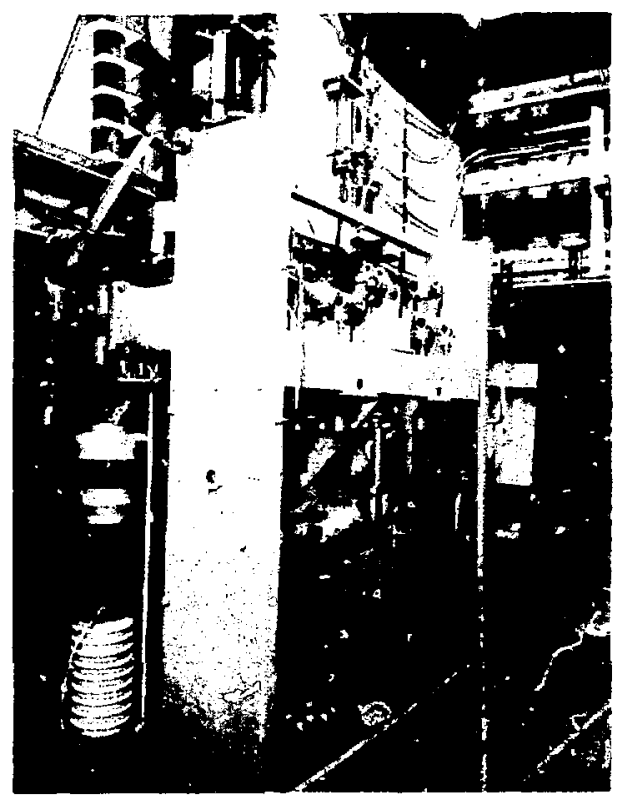

Fig. 23. Toshiba interrupter in tesi facility . 


\section{A. Defintition of Critical Parameters}

The instructions for operation of the interrupters, supplied in Toshiba dociment number KDPU-0005, revised July 25, 1978, Include a 11st of specifications under which the interrupters were to be operated. The critical parameters included in these specifications are displayed in Fig. 24 .

Table IV compares the Toshiba specifications with those experimentally obtained in the standard tests. The only specification exceeded in the test circuit was $\mathrm{di} / \mathrm{dt}$ | due to facility constraints. As will be seen later in the results, this had no effect on the rellability of interruption in the standard tests.

\section{Testing}

Inftially, approximately 150 single-interrupter tests were run at currents less than $24 \mathrm{kA}$. The purpose of these inftial tests was twofold. First of all, the facility and its components had to be checked at low current levels. This included verification of ignitron and breaker timings, establishment of proper voltage-current relationships, and adjustment of the data acquistition equipment. The inftial low-current tests also helped to condition the vacuum interrupters by absorbing stray gasses that might be present in the vacuum chamber.

\section{TABLE IV}

COMPARISON OF TOSHIBA SPECIFICATIONS

WITH THOSE EXPERTMENTALLY OBTAINED

\section{Parameter}

I INT $_{\text {IN }}$

$\left.\frac{d 1}{d t}\right|_{m}$

$\frac{d t}{d t} \mid z$

$V_{\mathbf{P}}$

$\mathbf{V}_{\mathbf{N}}$

$\frac{d V}{d t} P$

$\frac{d V}{d t} / N$

$\mathrm{T}_{\text {ARC }}$

\section{Definition}

Interruptic, current, $\mathrm{kA}$

Mean rate of current $\mathrm{fa} 11, \mathrm{~A} / \mu \mathrm{s}$

Mean rate of current fall

near current zero, A/ $/ \mathrm{s}$

Peak recovery voltage, $\mathrm{kV}$

Peak Inverse voltage, kV

Rate of rise of recovery voltage $V / \mu s<300$

Rate of rise of inverse voltage, $V / \mu s<300$

Arcing time, ms
Toshiba Spectfication

24

$<96$

$<26$

$<25$

$<25$
3.9

103

108

Experimental

Value

$$
24
$$

26

24.6

8 
The interrupters were then connected in series, and the current was gradually increased in another series of tests. This procedure of increasing the current in several discrete steps was followed every time the facility had been inoperative for a period of several hours or mora to condition the ignitrons for full voltage. Figure 25 shows the current waveform for a typical 24-kA interruption. The second picture is a magnification of the current just prior to interruption and 1llustrates the effect of the saturable reactor. Figure 26 includes the corresponding voltage waveforms for a typical interruption. The second picture shows the inverse voltage in detail.

Another measurement taken routinely during the standard tests was of displacement versus time for the moveable contact of Toshiba interrupter No. 1 . This was to help detect any changes in the actuator movement due to wear or loosening of parts. A displacement transducer with a 25-kHz excitation frequency provided the displacement curve shown in Fig. 27. The displacement curve remained constant throughout the standard tests indicating a very consistant actuator movement.

\section{Circuit Idiosyncracies}

Two circuit idiosyncracies were observed during the standard tests; both affected the recovery voltage characteristics. The first occurred when the $1-k \Omega$ resistor falled to hold the counterpulse ignitrons in a conducting state after current interruption. The voltage on the snubber capacitor across the interrupter then decayed through the $1-\mathrm{k} \Omega$ resistor with a $7.5-\mathrm{ms}$ time constant. In a normal test sequence this time constant is approximately $5 n 0 \mathrm{~ms}$. This abnormality is referred to as a "voltage droop" and is pictured in Fig. 28.

The second abnormality occurred when the blocking circuit failed to hold the voltage on the counterpulse capacitor. The capacitor voltage would then oscillate with the 200- $\mathrm{H}$ inductor for one-half or more cycles until the blocking circuit did interrupt. The result was an oscillatory recovery voltage such as that pictured in Fig. 29. In both types of abnormalities the peak recovery voltage is the same as in a normal shot.

D. Results from Standard Tests

Table $V$ gives a summary of standard tests performed on the Toshiba interrupter.

TABLE V

SUMMARY OF STANDARD TESTS ON TOSHIBA INTERRUPTER

\begin{tabular}{|c|c|c|c|c|c|c|c|c|c|c|}
\hline $\begin{array}{l}\text { Description of } \\
\text { Test Condition }\end{array}$ & Type & $\begin{array}{c}\text { Interruption } \\
\text { Current } \\
\text { (kA) }\end{array}$ & $\begin{array}{r}V_{p} \\
(k v) \\
\end{array}$ & $\begin{array}{r}\mathrm{v}_{\mathrm{N}} \\
(k \mathrm{~V}) \\
\end{array}$ & $\begin{array}{r}\left.\frac{d v}{d t}\right|_{P} \\
\quad(v) \\
\end{array}$ & $\begin{array}{l}\left.\frac{d v}{d t}\right|_{N} \\
\mu s) \\
\end{array}$ & $\begin{array}{r}\left.\frac{d 1}{d t}\right|_{M} \\
(A\end{array}$ & $\begin{array}{l}\left.\frac{d i}{d t}\right|_{2} \\
s)\end{array}$ & $\begin{array}{l}\text { No. of } \\
\text { Shots } \\
\end{array}$ & $\begin{array}{l}\text { ilo. of } \\
\text { Failures }\end{array}$ \\
\hline $\begin{array}{l}\text { SLartup } \\
\text { Startup } \\
\text { Oscdllatory }\end{array}$ & $\begin{array}{l}\text { Single } \\
\text { Series }\end{array}$ & $\begin{array}{l}5-24 \\
5-23\end{array}$ & $\begin{array}{l}6-25 \\
6-24\end{array}$ & $\begin{array}{l}<3.9 \\
<3.9\end{array}$ & $\begin{array}{l}<103 \\
<103\end{array}$ & $\begin{array}{l}<108 \\
<108\end{array}$ & $\begin{array}{l}<133 \\
<133\end{array}$ & $\begin{array}{l}<26 \\
<26\end{array}$ & $\begin{array}{l}153 \\
194\end{array}$ & $\begin{array}{l}0 \\
0\end{array}$ \\
\hline $\begin{array}{l}\text { Recovery } \\
\text { Decaying }\end{array}$ & Series & 24 & 25 & 3.9 & 103 & 108 & 133 & 26 & 58 & 0 \\
\hline $\begin{array}{l}\text { Recovery } \\
\text { Flat } \\
\text { Recovery }\end{array}$ & Sertes & 24 & 25 & 3.9 & 103 & 108 & 133 & 26 & 143 & 0 \\
\hline
\end{tabular}



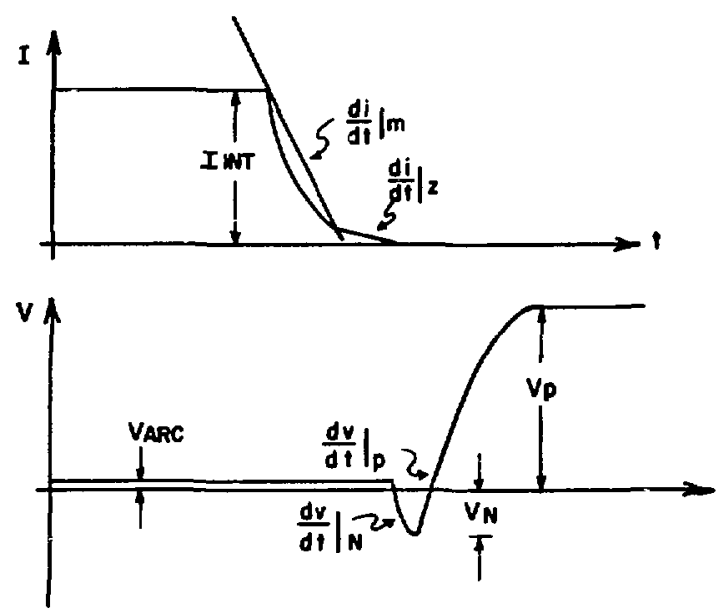

Fig. 24. Critical test parameters.

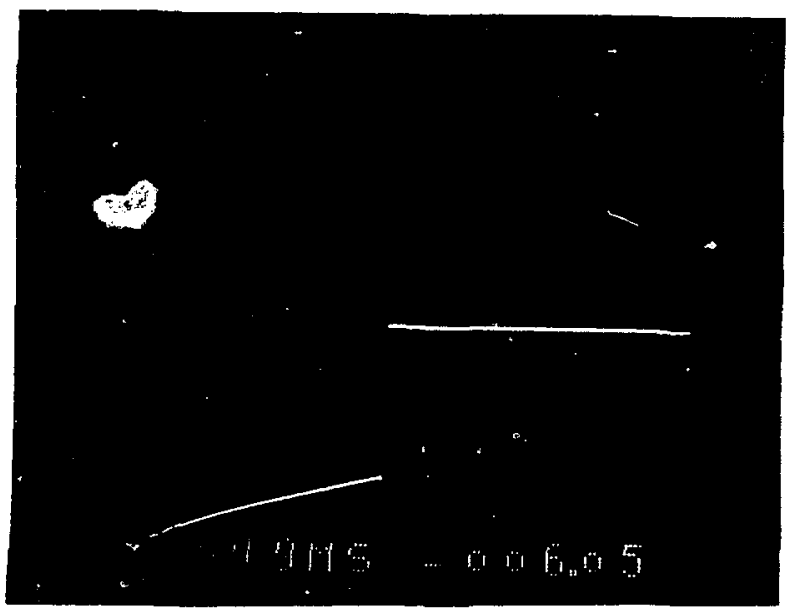

(a)

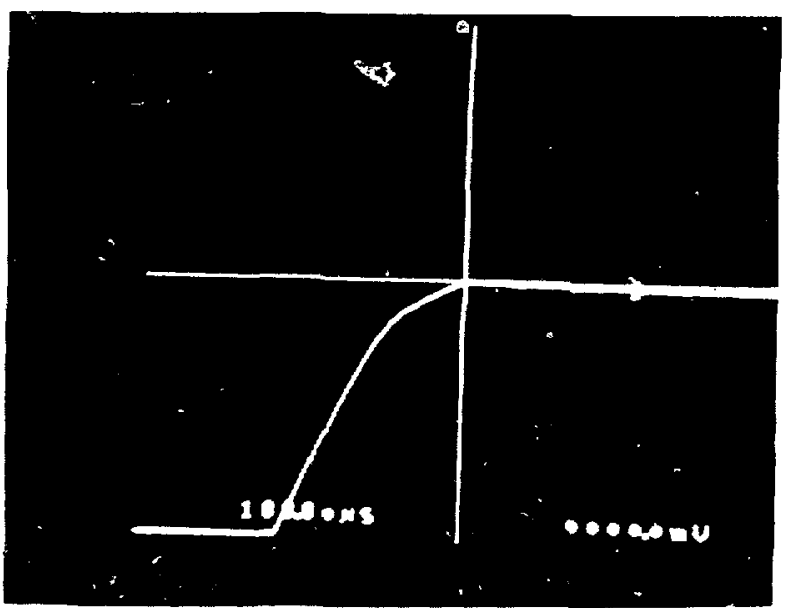

(b)

Fig. 25. Current waveforms for typical 24-kA interruption.

(a) Full current waveform.

(b) Magnification near current zero. 


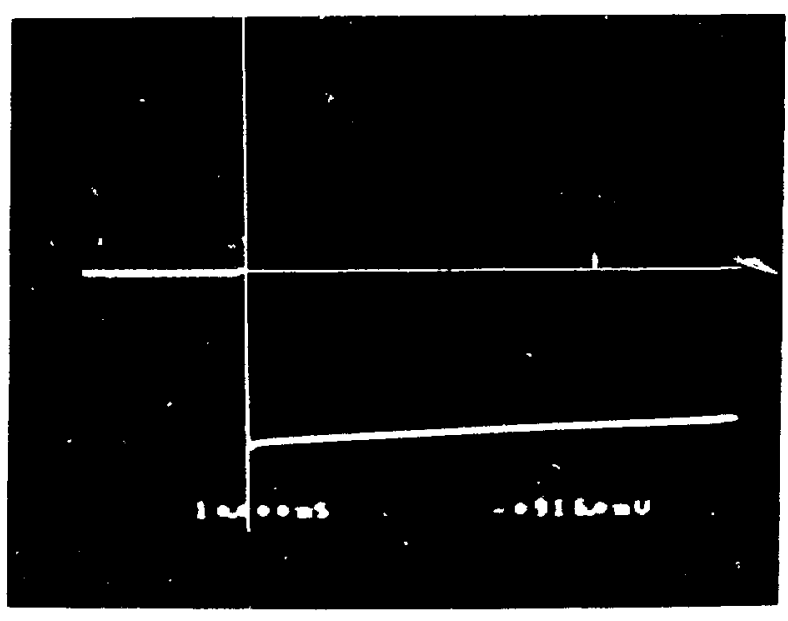

(a)

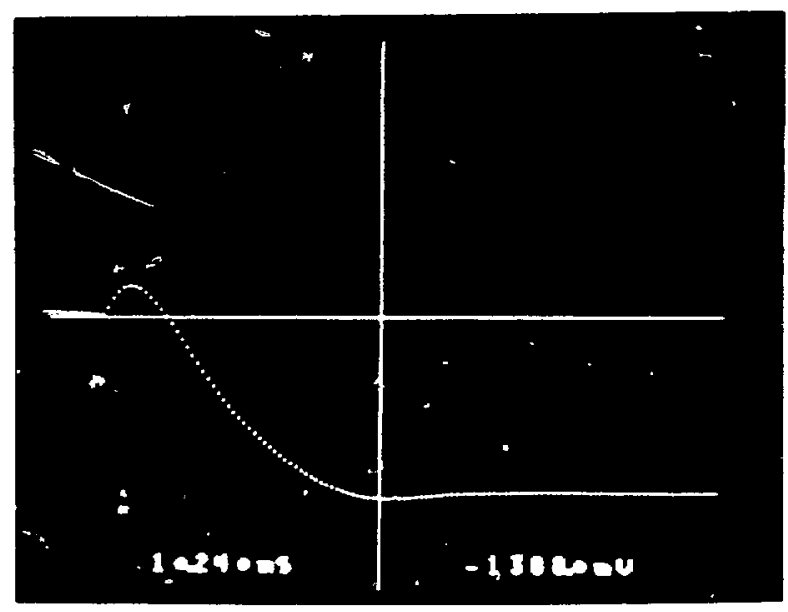

(b)

Fig. 26. Voltage waveforms for typical 24-kA interruption.

(a) Full voltage waveform.

(b) Magnification of inverse voltage.

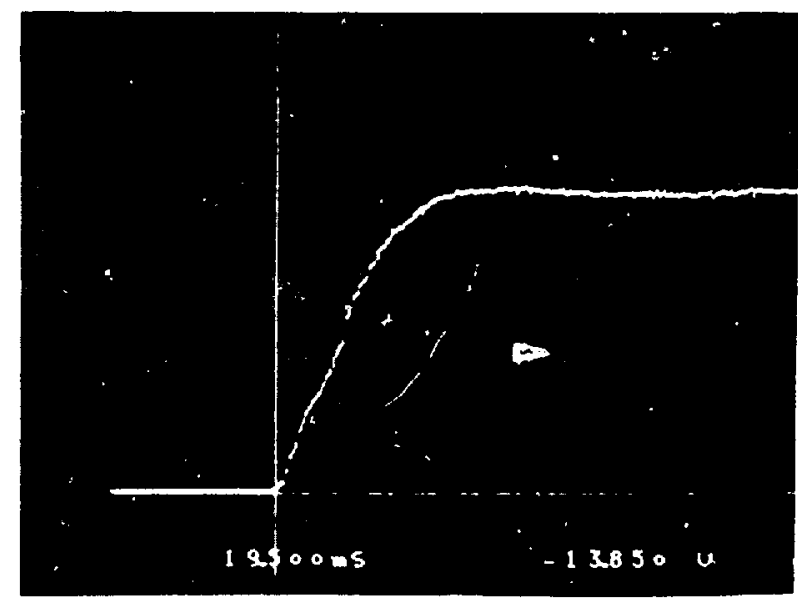

Fig. 27. Displacement vs time for Toshiba interrupter No. 1.

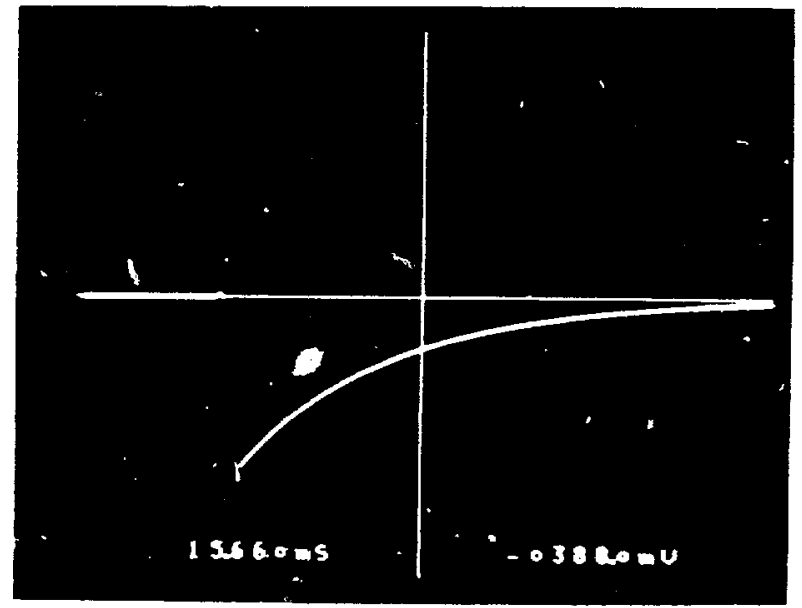

Fig. 28. Voltage droop across interrupter. 


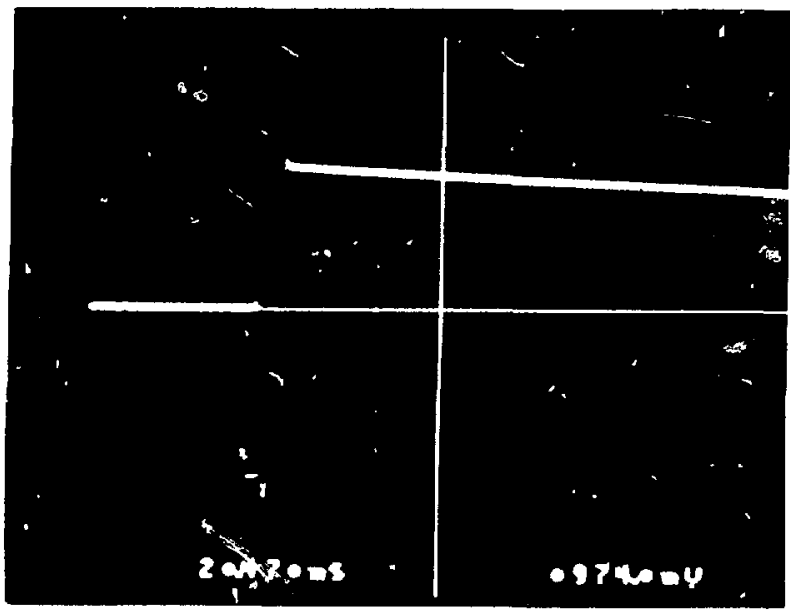

Fig. 29. Oscillitory recovery voltage, one-half cycle.

As can be seen, there were no fallures to interrupt on any of the 1145 serfes-connected, fuli-level tests. In addition, the midpoint voltage between the two interrupters was carefully monftored during the course of testing and revealed that there were no single-interrupter restrikes. Both the full and midpoint voltages were observed for $30 \mathrm{~ms}$ after interruption.

\section{E. Eroston}

Erosion measurements were routinely made at the beginning of each day's testing on both vacuum interrupters. This was accomplished by inserting a depth micrometer through guide plates mounted above each moveable contact. The micrometer armature was lowered until it came in contact with the coupling attached to the stem of the moveable electrode. The net erosion as a function of the total number of 24-kA shots is plotted ir Fig. 30. Minor indications of growth or erosion are probably a result of slight changes in the seating of the moveable electrode. The major trend indicites an initial erosion rate of approximately $0.2 \mathrm{~mm} / 1000$ shots for the first 600 shots. Following this, there appears to be an abatement of erosion. The earlier tests in which an interrupter was cut open after a similar series of tests, have shown a net migration of material from one electrode to another. Thus, erosion in the normal sense of the word is not directly applicable to the process which takes place between the electrodes of a vacuum interrupter. The fallure mechanisms of vacuum interrupters are still not well known, but it is generally felt that their 11fetime is not proportional to the thickness of the electrodes.

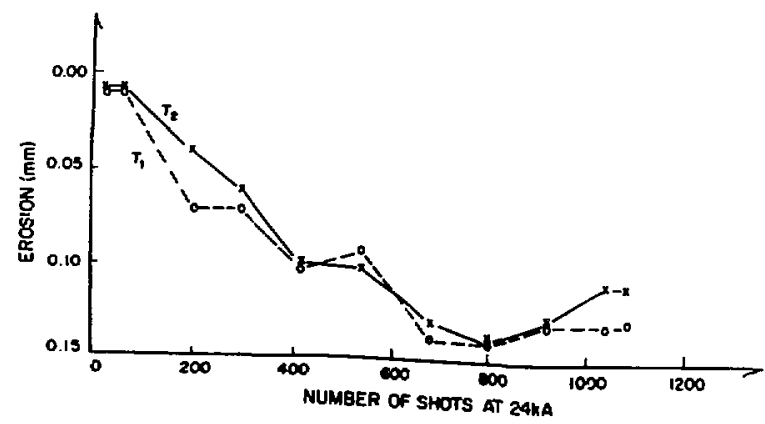

Fig. 30. Erosion of Toshiba interrupters. 


\section{EXTENDED TESTS}

Single-interrupter tests were run on a Toshiba interrupter to determine its maximum interrupting capabilities. The parameter $\mathrm{d} f / \mathrm{dt} / \mathrm{Z}$ was kept below $100 \mathrm{~A} / \mu \mathrm{s}$ for currents below $40 \mathrm{kA}$ and below $50 \mathrm{~A} / \mu \mathrm{s}$ for currents between 40 and $45 \mathrm{kA}$. Fig. $31 \mathrm{is}$ a schematic of the circuit used for these extended tests.

The circuit is similar to the previous one except it lacks a blocking interrupter. Instead, the 100- $\mu \mathrm{H}$ inductor is allowed to ring with the counterpulse capacitor for one-half cycle. This results in a sinusoidal shaped recuvery voltage waveform. At the end of the one-half cycle the 0.01-ohm resistor is inserted parallel to the inductor. This quickly damps out any further ringing of the L-C circuit. It should also be noted that the saturable reactor has been changed and that the counterpulse and snubber networks are adaptable to either a $40-$ or $60 \mathrm{kV}$ configuration.

\section{A. Testing}

Figure 32 shows a typical recovery voltage waveform for the extended tests. The second photograph shows an expanded view of the inverse voltage.

A total of 51 tests was rade with the circuit of Fig. 31 at currents ranging from 35 to $45 \mathrm{kA}$. Peak recovery voltages were from 24 to $33 \mathrm{kV}$. Six fallures were observed, all at currents in excess of $40 \mathrm{kA}$. Figure 33 shows the voltage waveform for one such fallure. Although this fallure occurred after the voltage peak, most fallures took place prior to the peak. Occasionally the interrupter would restrike on the inverse voltage but recover sufficlently to hold off the forward recovery voltage. Figure 34 1llustrates this phenomenon which is referred to as a second-zero interruption.

Another set of extended tests was performed utilizing second-zero incerruption with an ungapped saturable reactor Identical to that used in the teits of Westinghouse interrupters. This reactor has the advantage of a very high unsaturated-to-saturated inductance ratio as well as being simple to construct and modify. The counterpulse essentially drives the interrupter current slightly through zero and then reapproaches the zero crossing with a vely low $\mathrm{d} f / \mathrm{dt}$. Figure 35 shows a typical current waveform for this type of interruption. Here the inverse current is $250 \mathrm{~A}$, and $\mathrm{di} / \mathrm{dt}$ prior to the sacond-zero crossing is $10 \mathrm{~A} / \mu \mathrm{s}$.

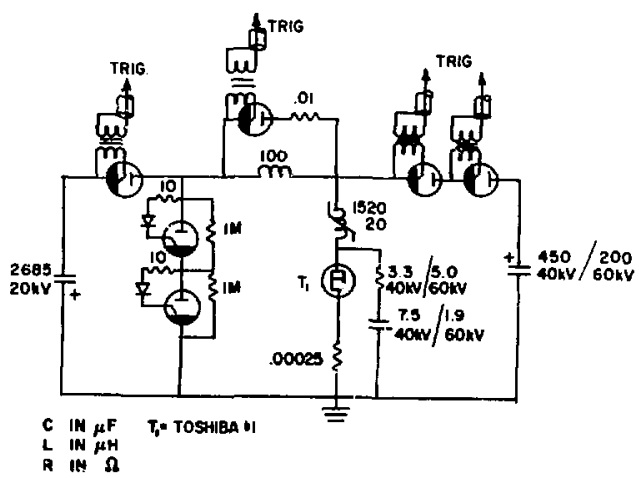

Fig. 31. Circuit for cxtended tests. 


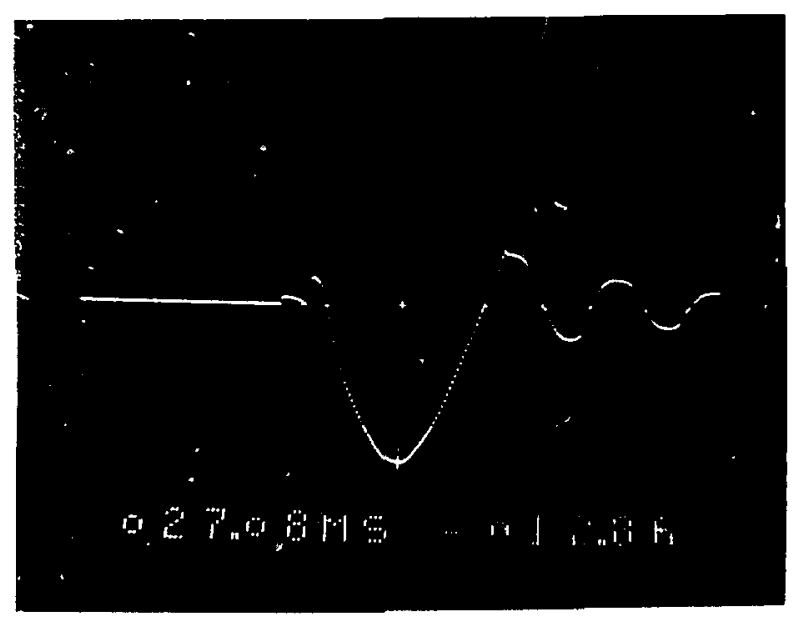

(a)

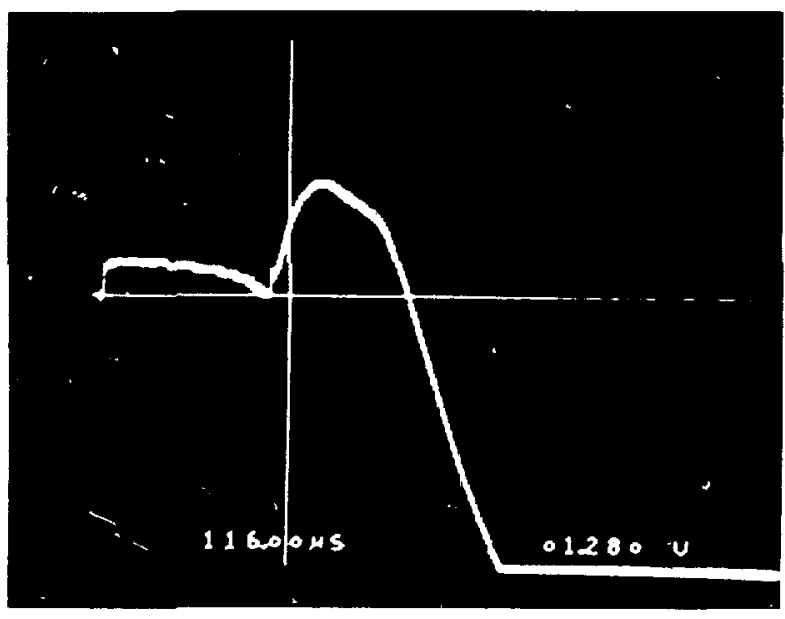

(b)

Fig. 32. Recovery voltage waveform for extended tests.

(a) Full voltage waveform.

(b) Expanded inverse voltąe.

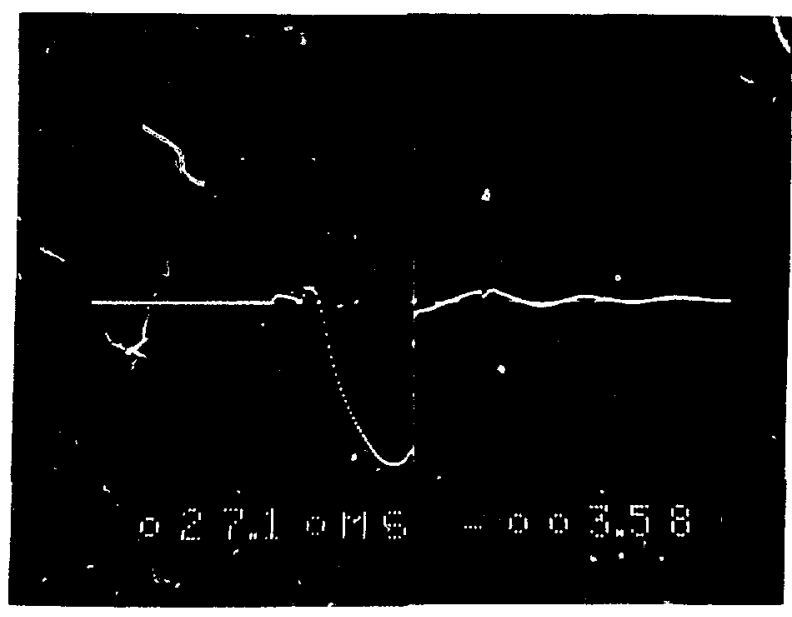

Fig. 33. Voltage restrike afte: 45-kA interruption.

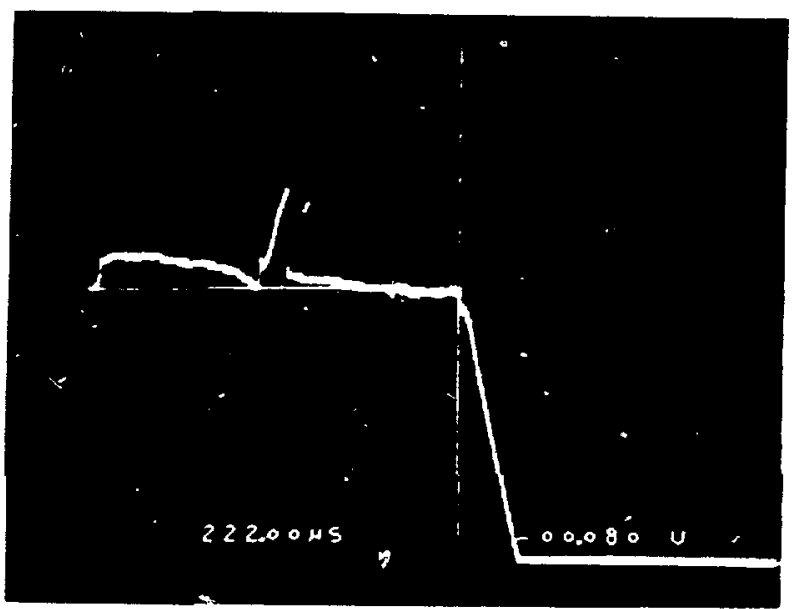

Fig. 34. Restrike on inverse voltage (expanded view). 


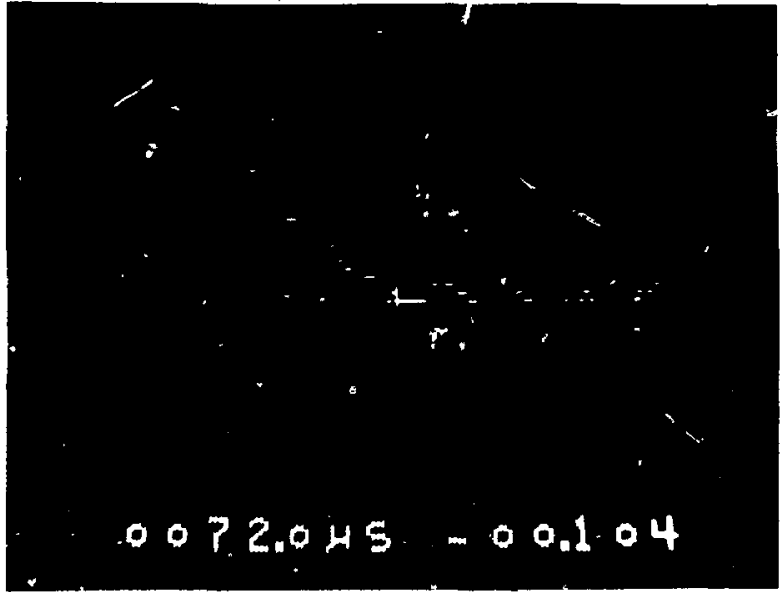

Fig. 35. Second current-zero interruption with ungapped saturable reactor.

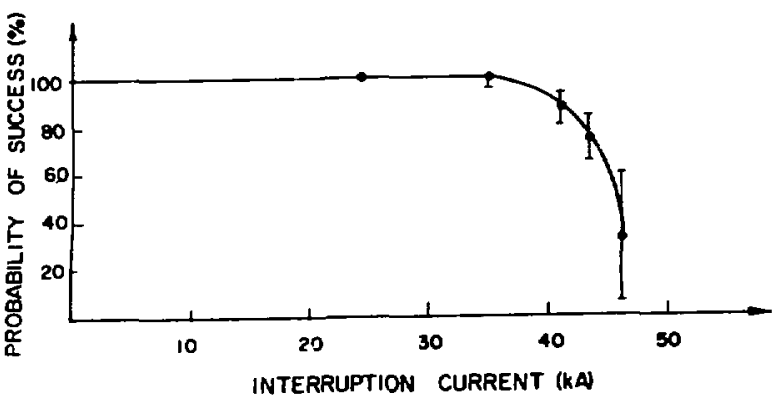

Fig. 36. Probability of interruption for single Toshiba interrupter.

A total of 26 tests was made in the above described way with currents ranging from 35 to $47 \mathrm{kA}$. Four failuras were observed, a11 above $42 \mathrm{kA}$. These fallures involved restrikes on the voitage rise from 6 to $18 \mathrm{kV}$. Successful recovery voltages ranged from 25 to $33 \mathrm{kV}$ peak.

\section{B. Results from Extended Tests}

Table VI is a summary of the extended test results taken on a single Toshiba interrupter. From these data, the performance of the interrupter appears to be fairly independent of tire type of saturable reactor used. By combining the results of tests with both types of saturable reactors, the probability of interruption curve shown In Fig. 36 can be constructed.

TABLE VI

SUMMARY OF EXTENDED TESTS ON TOSHIBA INTERRUPTER

Mescription of Test Condition

Gapped Saturable Reactur

Uirgapped Sacurable Reactor

$$
\begin{gathered}
\text { Interruption } \\
\text { Current }
\end{gathered}
$$

Type

Single

Single

single

Single

Single

Single

single

single
35

33- 37

$40,-42.5$

$42.5-45.0$

$34-37$

$40 .-42.5$

$42.5-45.0$

$45.0-47.5$

$$
\mathrm{v}_{\mathrm{p}}
$$

(kV)

$\left.\left.v_{P} \quad v_{N} \quad \frac{d V}{d t}\right|_{P} \quad \frac{d V}{d t}\right|_{N}$

(kv)

(v/Hs)

24
$30-33$

24-25

25-26

6
5
4

6
5
4
3

$25-26$

29-30

30- 31

$31-32$
-
120

490

130

200

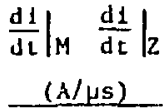

3000

290

110

100

380

430

390

410
No. of

Shots

$\begin{array}{lll}- & 1200 & 10 \\ - & 1300 & 10 \\ - & 1300 & 10 \\ - & 1300 & 10\end{array}$

\section{shots}

-

$\begin{array}{r}34 \\ -\quad 390 \\ -\quad 430 \\ \hline\end{array}$

340
390
430
440

\begin{abstract}
נ3no
\end{abstract}

37
43
43
40

10
10
10
10

$\begin{array}{rl}10 & 0 \\ 11 & 0 \\ 22 & 3 \\ 8 & 3 \\ & \\ 10 & 0 \\ 1 & 0 \\ 12 & 2 \\ 3 & 2\end{array}$


From this graph, the $90 \%$ and $50 \%$ success points are 41 and $46 \mathrm{kA}$, respectively. This ts in general agreement with previous findings at LASL for similar sized interrupters with internal axlal flelds. It must be noted that this is a conservative estimate for the maximum ratings because of the following reason. Due to the decaying nature of the current waveform, the interrupter must be opened on approximately one and one-half times the current it is required to interrupt. If the arc at this higher current is not diffuse, then it is possible to form an anode spot. This anode spot would increase the restrike probability upon application of a recovery voltage due to thermolonic emission. Thus it is possible that a higher rating might be found if the device were tested with a flat current waveform.

IV. CONCLUSIONS

A total of 1145 tests was made on two series-connected Toshiba interrupters at $24 \mathrm{kA}$ and $25 \mathrm{kV}$. No fallures to interrupt occurred during any of these tests. In addition, no single interrupter restrikes were observed. The contact erosion rate was monitored and found to be $0.2 \mathrm{~mm} / 1000$ shots for the first 600 tests. During the remaining tests there appeared to be no further erosion.

Extended tasts were performed to find the upper-1imit interruption ability on a single interrupter. The $90 \%$ and $50 \%$ rellability points are 41 and $4.6 \mathrm{kA}$, respectively. These points are valid for recovery voltages between 24 and $33 \mathrm{kV}$.

\section{PART III - OVERALL CONCLUSIONS}

Two interrupter systems were tested for over 1000 interruptions each at $24 \mathrm{kA}$ and $25 \mathrm{kV}$. One system employed spectal Westinghouse interrupters in a clrcuit designed by LASL. This circuit used a commerclally avaflable actuator and a minimum size counterpulse bank and saturable reactor. The other used Toshiba interrupters actuated by a Toshiba mechanism in a Toshiba circuit ustng a larger counterpulse bank and saturable reactor.

Both of these systems successfully completed 1 no0 interruptions without fallure and indicated a very low contact erosion rate. Both appear to satiffy the needs of TFTR with respect to rellability and to have such low erosion rates that this feature is not expected to be a Iimitation on 1ifetime.

The superfority of the Toshiba system, 1.e., no single vacuum interrupter fallures versus three single interrupter failures for the Nestinghouse Interrupters, can be attributed to three major sources: a different circuit which imposes lower stresses on the Toshiba interrupters, a better Toshiba actuator which performs more rellably and predictably, and a larger vacuum interrupter with somewhat better characteristics. The relative contributions of these three factors are unknown.

The many problems encountered with the Ross actuator indicate that extensive development work should be spent on it before its further use is considered. 


\section{References}

1. R. W. Warren, "Experiments with Vacuum Interrupters Used for Large DC-Current Interruption," Los Alamos Scientific Laboratory report LA-6909-MS.

2. Semtech Corporation, Newbury Park, California.

3. Mode1 HA-75, available from Ross Englneering Corporation, Campbe11, California. 